\title{
TEXTO
}

\section{NATURALEZA A TRAVÉS DE LA BOTÁNICA Y ZOOLOGÍA EN LA LITERATURA RENACENTISTA ESPAÑOLA: LA CELESTINA}

\section{Manuel Pardo de Santayana y Antonio García-Villaraco}

Universidad Autónoma de Madrid

\section{Mar Rey Bueno}

Sociedad Española de Historia de la Alquimia

\section{Ramón Morales}

Real Jardín Botánico, CSIC. Madrid

\section{RESUMEN}

En este trabajo se analizan y cuantifican las referencias botánicas y zoológicas que aparecen en La Celestina como ejemplo de los conocimientos sobre plantas y animales que incorpora una obra de la literatura renacentista española. Dado el oficio de la protagonista, el interés del uso de muchas plantas y animales se centra en el cuidado, cura y aseo del cuerpo, que entonces se hacía sobre todo a base de productos vegetales y animales. Éstos también aparecen empleados en la magia de amor. Se comentan asimismo la utilización de nombres de plantas y animales, así como de productos derivados de éstos, como recursos lingüísticos o literarios; es decir, cuando se emplean como metáforas, en dichos, frases hechas y otras figuras literarias. Se incluyen en 2 anexos las 86 especies vegetales y las 70 animales, así como las citas encontradas.

PALABRAS CLAVE: Plantas. Animales. Naturaleza. Literatura. La Celestina.

NATURE IN BOTANY AND ZOOLOGY IN THE SPANISH LITERATURE: LA CELESTINA

\section{ABSTRACT}

The botanical and zoological references that appear in La Celestina are analysed and cuantified to provide an insight of the knowledge about plants and animals included in a literary work of the 
Rennaisance, in this case one of the most important of the Spanish literature. The plants and animals products were used by the healer for the care, health and beauty of the body. Many other plants, animals and some mineral products were used for love remedies. Moreover, references to plant and animal names and their products are also commented as linguistic sources, i.e. metaphoric references to plants, set phrases, and other literary figures of speech. All the 86 plant species and 70 animals and the complete textual passages are included in two apendixes.

KEY WORDS: Plants. Animals. Nature. Spanish literature. La Celestina.

\section{INTRODUCCIÓN}

En 1499 veía la luz, en las prensas burgalesas de Fadrique de Basilea, la Comedia de Calisto y Melibea, versión primitiva o corta de la obra que, con el título de Tragicomedia de Calisto y Melibea, se publicaría en los primeros años del siglo XVI ${ }^{1}$. Más conocida como La Celestina ${ }^{2}$, su autor es Fernando de Rojas, natural de Puebla de Montalbán, Toledo. Como obra maestra que es, de una profundidad y una riqueza significativa excepcionales, ha sido el origen de una bibliografía extensa y enfrentada que cubre los más variados aspectos ${ }^{3}$. El objetivo primordial del presente estudio consiste en identificar las plantas y animales que aparecen en La Celestina, tarea que no ha sido acometida en su totalidad hasta el momento actual. Esta identificación proporcionará al futuro investigador sobre temas celestinescos una herramienta de trabajo más, a la hora de interpretar costumbres, ideas, creencias y tradiciones propias de la época histórica en la que fue escrita y en la que se desarrolla la trama de La Celestina ${ }^{4}$.

1 No se sabe con exactitud la fecha de publicación de esta versión definitiva. La edición más antigua conservada corresponde a la publicada en Zaragoza por Jorge Coci en 1507, si bien no se trata de la princeps, puesto que ya en 1506 salió en Roma una traducción completa al italiano, realizada por Antonio Ordóñez. Whinnom, K. (1966), The Relationship of the Early Editions of the Celestina, Zeitschrift für Romanische Philologie, LXXXII, pp. 22-40.

2 Salvador Miguel, N. (2000), La Celestina en su V Centenario (1499/15001999/2000). En CARrasco, P. (ed.), El mundo como contienda. Estudios sobre La Celestina, Málaga, Universidad, pp. 15-27.

3 Por ejemplo, los repertorios bibliográficos de Schizzano MAndel, A. (1971), La Celestina Studies: A Thematic Survey and Bibliography 1824-1970, New Jersey, Metuchen, y de Snow, J.T. (1985), Celestina by Fernando de Rojas. An Annotated Bibliography of World Interest 1930-1985, Madison, Hispanic Seminary of Medieval Studies, o la revista Celestines$c a$ donde, junto a artículos y reseñas, se incluye una bibliografía periódica que recoge y compendia todo tipo de aportaciones sobre el libro.

4 La utilización de obras literarias como fuente de datos de todo tipo y su posterior análisis para desvelar conocimientos o actitudes ante ciertas cuestiones de la época histórica 


\section{UN LABORATORIO Y SEIS OFICIOS}

Como es bien sabido, La Celestina comienza cuando Calisto, un joven de origen noble, entra en el huerto de Melibea buscando un halcón que se le ha escapado ${ }^{5}$. Enamorado a primera vista de la doncella, solicita su amor, pero es bruscamente despreciado. Es entonces cuando Calisto pide ayuda a su criado Sempronio, quien le habla de Celestina, una vieja prostituta y ahora alcahueta profesional que, haciéndose pasar por vendedora de artículos diversos, entra en las casas y concierta citas de amantes. Buena parte de las referencias vegetales y animales presentes en La Celestina aparecen en este acto primero, con motivo de la descripción que hace Pármeno, también criado de Calisto, de la vivienda celestinesca. El joven Pármeno es hijo de Claudina, maestra y compañera de Celestina, y dice de esta que es labrandera, perfumera, maestra de hacer virgos y afeites, alcahueta y hechicera, Celestina es el personaje más sugestivo de la obra, hasta el punto de que acabó por darle título.

La minuciosa descripción de los afeites y confecciones, aguas de olor y tintes capilares, untes y mantecas, hierbas y raíces, aceites de rostro y hechizos diversos fue analizada en detalle por Modesto Laza Palacios hace medio siglo ${ }^{6}$, buscando el uso que Celestina daba a todas esas sustancias en la obra que más información podía suministrarle, la versión castellana del Dioscórides hecha por el médico segoviano Andrés Laguna a mediados del siglo $\mathrm{XVI}^{7}$. Tanto Laza Palacios como buena parte de los seguidores de su obra se

correspondiente ha dado lugar a interesantes conclusiones. Ver, por ejemplo, nuestras aportaciones al respecto en Heinrich, M., Kufer, J., Leonti, M. y Pardo de SANTAyana, M. (2006), Ethnobotany and ethnopharmacology - Interdisciplinary links with the historical sciences, Journal of Ethnopharmacology, 107 (2), pp. 157-160, y PARDO DE SANTAYANA, M., Tardío, J., Heinrich, M., Touwaide, A. y Morales, R. (2006), Plants in the works of Cervantes, Economic Botany, 60 (2), pp. 159-181. También hay otras como el estudio de los animales que aparecen en El Quijote (Aguilar, A.L. y VIEJO, J.L. (2005), El oido. Ecofonías del Quijote. En GARCÍA MARTín, P. (ed.), El Quijote en la cultura popular. "Las imágenes pobres y los cinco sentidos", pp. 143-152, Junta de Castilla y León); o de Shakespeare (ELLACOMBE, H.N. (1884), The Plant-lore and Garden-craft of Shakespeare, London, W. Satchell and Co.; o las referentes a La Biblia (Moldenke, H.N. y Moldenke, A.L. (2002), Plants of the Bible, London, Kegan Paul).

5 Se ha utilizado la $4^{\mathrm{a}}$ edición (Madrid, 1977) que Bruno Mario Damiani hizo para Ediciones Cátedra.

6 Laza Palacios, M. (1958), El Laboratorio de La Celestina, Málaga, Antonio Gutiérrez Impresor.

7 Laguna, A. (1555), Pedacio Dioscorides Anazarbeo, Acerca de la Materia Medica y de los venenos mortiferos, Amberes, Juan Latio. 
han centrado básicamente en el uso mágico que, en los tiempos de Celestina, se daba a todas estas sustancias ${ }^{8}$. Indudablemente, la magia es uno de los principales atractivos de Celestina y puede considerarse como elemento fundamental dentro de la trama, si bien nuestra protagonista es mucho más que una hechicera al uso ${ }^{9}$. Los seis oficios que Pármeno cita son otras tantas formas de acercamiento al mundo cotidiano femenino de la época y ninguno de ellos puede entenderse al margen de los demás. Punto de encuentro de todos ellos es la naturaleza, el uso de sustancias extraídas de vegetales, animales y minerales y que, según el oficio que emplee nuestra protagonista, tendrán aplicaciones distintas.

Desde que Laza Palacios publicara su estudio hasta el momento actual se han abierto numerosas vías de investigación que tienen como punto de partida la mujer y sus circunstancias en el umbral de la Edad Moderna. Lo que, durante mucho tiempo, fue considerado como un laboratorio extraordinario y único puede ser, exclusivamente, el mejor fresco literario de lo que ocurría habitualmente en la sociedad que presenció la publicación de La Celestina. En efecto, vemos cómo la mujer desempeñó un papel fundamental en la medicina doméstica y no sólo como partera, labor tradicionalmente asignada al universo femenino, sino como conocedora de remedios para resolver los problemas de salud más comunes en el espacio doméstico ${ }^{10}$. Tarea que compaginaba con la de perfumista y cosmetóloga, encargada de la limpieza y ornato del cuerpo a través de la actuación sobre la piel, la higiene bucal y el cabello ${ }^{11}$. Conocimientos diver-

8 Folchjou, G., García Domínguez, P. y Muñoz Calvo, S. (1977), La Celestina: ¿hechicera o boticaria? En CRIADO DEL VAL, M. (coord.), La Celestina y su contorno social: actas del I Congreso Internacional sobre La Celestina, Madrid, Hispam, pp. 163-167; ALBARRACÍN NAVARro, J. y MARTínez RuIZ, J. (1977), Farmacopea en La Celestina y en un manuscrito árabe de Ocaña. En CRIADO DEL VAL (coord.) (1977), pp. 409-426 (trabajo que hace hincapié en el carácter marcadamente oriental del laboratorio de Celestina), y VIAN HERRERO, A. (1990), El pensamiento mágico en Celestina, instrumento de lid o contienda, Celestinesca, 14 (2), pp. 41-91 (el análisis pormenorizado de las sustancias medicinales, cosméticas y mágicas, tomando como fuente básica de información a Laza Palacios, en pp. 50-61).

9 El papel de la magia en La Celestina es uno de las principales polémicas que enfrenta a la crítica celestinesca desde sus inicios mismos. Entre los muchos escritos sobre el tema destaca Russel, P. (1978), La magia, tema integral de La Celestina. En Temas de La Celestina y otros estudios. Del Cid al Quijote, Barcelona, Ariel, pp. 243-276. Para una revisión en profundidad remitimos a VIAN HERRERO (vease nota anterior).

10 Martínez CresPo, A. (1994), Mujer y medicina en la Baja Edad Media, Hispania, 54 (186), pp. 37-52.

11 CABré I PAiret, M. (2002), Cosmética y Perfumería en la Castilla bajomedieval. En García Ballester, L. (ed.), Historia de la ciencia y de la técnica en la Corona de Castilla. Vol. II. Edad Media, Valladolid, Junta de Castilla y León, pp. 772-779. 
sos cuyas recetas y fórmulas no sólo se transmitían de forma oral sino que se compilaban en recetarios que iban pasando de madres a hijas como verdaderos tesoros de saber cotidiano ${ }^{12}$. Se trata de textos escritos por mujeres, aunque también pueden encontrarse algunos ejemplares redactados por hombres y destinados al público femenino. Tal es el caso de Flos de las medicines, ò receptes del tresor de Beutat, escrito por el valenciano Manuel Dies de Calatayud, mayordomo de Alfonso el Magnánimo ${ }^{13}$, o el muy interesante Sefer ahabat našim, manuscrito hebreo producido en la zona catalana en el que aparece un marcado componente mágico ausente en los otros ejemplos citados ${ }^{14}$.

La actuación primordial de Celestina como alcahueta ha centrado el discurso de los estudiosos en los aspectos más negativos de su tarea, a saber, la preparación de afeites y perfumes y su labor como hechicera. Moralistas y misóginos de la Edad Moderna encontraron en el uso de cosméticos el pretexto perfecto para criticar a las mujeres ${ }^{15}$; teólogos e inquisidores pretendían demostrar que la afición de la mujer a la magia y la brujería hacían de ella el agente perfecto del demonio ${ }^{16}$. En ambos casos las plantas ocupan una posi-

12 Entre los ejemplos más antiguos conservados se encuentra el Manual de mugeres en el qual se contienen muchas y diversas reçeutas muy buenas, conservado en la Biblioteca Palatina de Parma (mss. 834) y del que Alicia Martínez Crespo ha hecho una edición con un interesante estudio introductorio (Salamanca, Universidad, 1995). La Biblioteca Nacional de Madrid conserva tres estupendos ejemplares del siglo XVI, en los que se mezcla terapéutica, cosmética y cocina: el Livro de receptas de pivetes, pastilhas elvvas perfumadas y conserbas (ms. 1462), las Receptas experimentadas para diversas cosas (ms. 2019) y las Recetas y memorias para guisados, confituras, olores, aguas, afeites, adobos de guantes, ungüentos y medicinas para muchas enfermedades (ms. 6058). Recetarios que han sido analizados en PÉREZ SAMPER, M. ${ }^{2} A$. (1997), Los recetarios de mujeres y para mujeres. Sobre la conservación y transmisión de los saberes domésticos en la época moderna, Cuadernos de Historia Moderna, 19, pp. 121-154.

13 Flores del Tesoro de la Belleza. Tratado de muchas medicinas o curiosidades de las mujeres (Introducción de Teresa $M^{a}$ Vinyoles. Prólogo de Josefina Roma. Traducción de Oriol Comas), Palma de Mallorca, José J. de Olañeta editor, 1993.

14 El libro de amor de mujeres (Introducción, traducción e índices de Carmen Caballero Navas), Granada, Universidad, 2003.

15 Martínez Crespo, A. (1993), La belleza y el uso de afeites en la mujer del siglo XV, Dicenda, 11, pp. 197-221; COLÓN CALDERón, I. (1995), De afeites, alcoholes y hollines, Dicenda, 13, pp. 65-82.

16 Caro Baroja, J. (1967), Vidas mágicas e Inquisición, Madrid, Taurus; SÁnCHEZ ORTEGA, M.'H. (2004), Ese viejo diablo llamado amor. La magia amorosa en la España Moderna, Madrid, UNED; Monco REBollo, M. (2004), Demonios y mujeres: historia de una transgresión. En Tausiet, M. y Amelang, J.S. (eds.), El diablo en la Edad Moderna, Madrid, Marcial Pons, pp. 187-210. 
ción privilegiada. Flores, hierbas y raíces constituyen la materia prima esencial para elaborar toda suerte de aguas de olor, afeites y tintes, pero también sortilegios, hechizos y pócimas. El trinomio mujer-hechicera-plantas hunde sus raíces en la prehistoria, cuando la mujer recolectora comienza a acumular conocimiento sobre las propiedades ocultas de las plantas, saber que le permitía curar, pero también provocar enfermedades e, incluso, causar la muerte. Durante toda la Edad Media se va gestando una concepción negativa de la mujer, que aparecerá descrita como un ser especialmente afín a la noche, la luna, el misterio, la magia y los espíritus malignos. Retrato que culminará con la publicación, en 1486, del Malleus maleficarum (Martillo de brujas), obra de los inquisidores dominicos Heinrich Kraemer y Jacob Sprenger, punto de partida de la llamada caza de brujas de la Edad Moderna ${ }^{17}$. Desde las que recogen hierbas hasta las que tienen enfrentamientos con sus vecinos, cualquier mujer corre el riesgo de ser considerada bruja y sufrir las penas más graves. Siempre se ha creído que las plantas que utilizaban las definidas como brujas en sus hechizos y pócimas eran hierbas fantásticas, misteriosas y de compleja búsqueda y recolección. La realidad es bien distinta: se trata de plantas comunes y abundantes que crecían por doquier en escombreras y bordes de caminos. Entonces, ¿estamos ante plantas verdaderamente efectivas o se trata de simples ilusiones inquisitoriales? El estudio de la enteobotánica y la botánica oculta de los siglos XIII al XVII nos revela que los principios tóxicos de ciertos vegetales son los principales culpables de que numerosas personas fueran acusadas de brujería y de realizar actos diabólicos. En efecto, las plantas citadas con mayor frecuencia en libros de brujería y procesos inquisitoriales son, con diferencia, las pertenecientes a la familia de las solanáceas: estramonio, belladona, mandrágora, tabaco o beleño. No son pocos los estudiosos que afirman que las visiones mágicas individuales o colectivas que aseguraban haber tenido algunos procesados sólo serían el producto de la ingestión o aplicación de ungüentos o bebedizos compuestos por estas plantas, ricas en alcaloides psicotrópicos ${ }^{18}$.

Desde esta nueva perspectiva, Celestina, como otras muchas de sus congéneres, se nos presenta bajo una nueva faz. Lejos de ser una vieja loca que sólo

17 Delumeau, J. (1978), La peur en Occident, París, Librairie Arthème Fayard; LeVACK, B.P. (1987), The Witch-Hunt in Early Modern Europe, London, Longman; ClARCK, S. (1997), Thinking with Demons. The idea of witchcraft in early modern Europe, Oxford, Oxford University Press.

18 GÓMEZ FERNÁNDEZ, J.R. (1999), Las plantas en la brujería medieval (propiedades y creencias), Madrid, Celeste Ediciones; Morales, R. (1995), Plantas mágicas y brujería, Quercus, 110, pp. 7-8. 
busca su lucro personal engañando con sortilegios y filtros inocuos, Celestina es una sabia mujer, experta conocedora del mundo vegetal, fuente tradicional de alimentos y medicamentos. Lejos de ser una embaucadora, Celestina poseía una amplia sabiduría popular basada en el conocimiento del universo vegetal y sus principios tóxicos. Se ha señalado que, con toda probabilidad, tanto Celestina como sus correligionarias reales comenzasen su periplo por el proceloso mar de la magia como curanderas, empleando diferentes plantas tóxicas de benéficas propiedades en dosis pequeñas, pasando poco a poco a proporciones más elevadas, descubriendo así los efectos psicotrópicos que éstas poseían ${ }^{19}$. Flora medicinal que, según la dosis, se transformaba en satánica, favoreciendo todo tipo de visiones y creencias. Conocimiento codiciado y peligroso, que veía reforzada su actividad con el recitado de conjuros y oraciones demoníacas, cuyo papel era crear el escenario psicológico adecuado para llevar a cabo rituales de aojamiento, ligamen, maleficio o curación.

Así, cuando Celestina acude junto a su maestra Claudina a cementerios y encrucijadas con la caída de la tarde, no está llevando a cabo ningún ritual satánico, sino aplicando el conocimiento empírico heredado de generación en generación. Está comprobado que en suelos en los que abundan los nitratos y las sales amoniacales, ciertos vegetales pueden llegar a doblar la cantidad de alcaloides, elevando la proporción de sus principios activos. Es por este motivo por el que, en abundantes ocasiones, se cita la recolección de vegetales en cementerios y otros lugares ricos en materia orgánica, como bordes de caminos y algunas zonas más o menos desagradables, como escombreras y basureros, lo que hizo que estas plantas resultaran aún más misteriosas. Y aún hay más. Las brujas y hechiceras salían a última hora de la tarde a recolectar los ingredientes de sus filtros principalmente por dos motivos: el primero de ellos era, sin duda, por su propia seguridad, ya que no podían permitirse ser vistas por sus propios vecinos recogiendo plantas venenosas, pues serían culpadas inevitablemente de practicar brujería; el segundo era más sabio, pues conocían que estas plantas acumulan la mayor cantidad de principios activos mientras luce el sol, aumentando a lo largo del día y alcanzando el máximo durante la tarde, momento idóneo para recogerlas ${ }^{20}$.

Que las mujeres eran unas expertas conocedoras del mundo vegetal bien lo sabían los médicos y boticarios de la Edad Moderna, que recurrían a ellas

19 Huelga decir que nos encontramos ante un saber empírico, fruto de la experiencia continuada en el uso de plantas ricas en psicótropos y estupefacientes. El descubrimiento de estas sustancias químicas no se produce hasta finales del siglo XIX. De cualquier forma, que no se conocieran por la ciencia no quiere decir que sus efectos no estuviesen ahí.

20 GómEZ FERNÁNDEZ (1999), pp. 15-16. 
para abastecerse de los simples necesarios para elaborar los remedios medicinales. Bernardo Cienfuegos ofrece buena muestra de ello en su inédita Historia de las plantas [1626-1631] $]^{21}$ donde nos cuenta, entre otras muchas cosas, cómo eran mujeres herbolarias las encargadas de recorrer los alrededores de las ciudades y villas en busca de los simples medicinales que luego iban a ser utilizados en las reboticas 22 . Esto era así porque, según su propio testimonio, la sabiduría vegetal se encontraba en manos de la gente común y, más concretamente, de las mujeres del campo, encargadas de curar las dolencias de su familia ante la ausencia habitual de médicos o la imposibilidad de pagar sus elevados honorarios ${ }^{23}$. Conocimiento femenino que fue utilizado por los autores de los denominados Libros de Secretos, género literario propio del Renacimiento. En dichos libros se compilaban toda suerte de recetas medicinales, cosméticas y metalúrgicas extractadas, por lo general, del acervo popular ${ }^{24}$. Las herbolarias no sólo eran capaces de distinguir multitud de especies vegetales en sus excursiones campestres sino que, una vez de regreso a sus casas,

21 Se trata de siete voluminosos tomos manuscritos, conservados en la Biblioteca Nacional de Madrid (BN) (mss. 3357-3363). Ver Blanco Castro, E., Morales, R. y SÁnchez Moreno, P. (1994), Bernardo Cienfuegos y su aportación a la botánica en el siglo XVII, Asclepio, 46 (1), pp. 37-123. Sobre su importancia en el ambiente científico de la época ver REY Bueno, M. (2004a), Juntas de herbolarios y tertulias espagíricas: el círculo cortesano de Diego de Cortavila (1597-1657), Dynamis, 24, pp. 243-267.

22 «En España los médicos son tuertos, los boticarios ciegos, ni gastan el uno ni otro sino lo que quisiere traher la mugercilla ygnorante diciendo que es Meliloto», BN, ms. 3362, fol. 244.

23 «El verdadero aunque vulgar conocimiento de las plantas se ha ido confirmando de mano en la gente común de el campo y en muchos linages de personas que aun hasta hoy se curan y medicinan sin médicos y boticarios con el modo que heredaron y aprendieron de sus pasados. Yo tube una agüela que murió con robusta salud y vista y llego a edad de ciento y quince años que llamaban la de Antón a causa que se llamó assi su marido: esto como digo digo llegó a ver entre hijos, nietos, bisnietos y choznos más de doscientas personas y en estando enfermos mientras vivió a todos sirvió de medico cirujano y boticario», BN, ms. 3362, fol. 530. Recuerda Cienfuegos cómo su abuela, ya siendo vieja y estando medio ciega, le enviaba a su huerta a por cinco en rama, para curar diversos tipos de dolencias, y era capaz de distinguirla al tacto porque sus raíces tenían «como escrófulas o turmillas». El de su abuela no es el único testimonio que recoge Cienfuegos. Así, hablando de la melisa llamada torongil, cuenta: «Aunque es verdad que es planta rara quien quisiere verla la hallará en Madrid en los barrancos detrás del rastro donde vacían los vientos y inmundicias de las calles que matan adonde casi todo el año se conserva verde con la misma pintura y delineación que ponen Galeno y Clusio. Una buena vieja de las que llaman en Castilla curanderas me enseñó esta planta y preguntándole el nombre me dijo que es abogada del mal de rabia», BN, ms. 3359, fol. 95.

24 Eamon, W. (1994), Science and the Secrets of Nature: Books of Secrets in Medieval and Early Modern Culture, Princeton, Princeton University Press. 
seguían todo el proceso necesario para secarlas y extraer de ellas las virtudes medicinales a través de laboriosos procesos. Así, cuando Pármeno nos dice que Celestina «tenía una cámara llena de alambiques, de redomillas, de barrilejos de barro, de vidrio, de arambre, de estaño, hechos de mil faciones» no hacía sino describir el laboratorio de destilación que la alcahueta tenía en su vivienda. Estamos, sin duda alguna, ante uno de los testimonios más interesantes sobre los saberes de Celestina: su faceta como destiladora. La destilación, entendida en la época como el arte o modo de extraer la virtud de una sustancia por la fuerza del fuego, es una de las técnicas que más impronta tuvo en la sociedad de la Edad Moderna ${ }^{25}$. El punto de partida de cualquier destilación pasaba por la extracción de los principios activos en medios alcohólicos. Para ello se dejaban macerar durante días los simples vegetales en espíritu de vino o aguardiente. A continuación se sometía al proceso destilatorio propiamente dicho: el resultado de la maceración se calentaba, las esencias extraídas por disolución en alcohol se volatilizaban y ascendían por el serpentín para acabar licuándose en el refrigerante y cayendo en forma de líquido sutil. Las sustancias así obtenidas recibían el nombre de aguas por su aspecto acuoso y podían ser, a grandes rasgos, simples, cuando se destilaba una única planta, o compuestas, cuando se destilaban dos o más. Todo este proceso requería la intervención de un horno, elemento indispensable en cualquier laboratorio, y de diferentes vasos de vidrio, por ser éste el material más adecuado para retener los espíritus sutiles y, fundamentalmente, porque evitaban la contaminación de la muestra que se producía al emplear recipientes de estaño, plomo o cobre. Práctica habitual de médicos, boticarios, metalúrgicos y alquimistas, investigaciones recientes apuntan también a las mujeres como practicantes de este complejo arte $^{26}$. El mismo año que salía a la luz la versión primitiva de La Celestina el boticario cordobés Sancho de Jaén compró «100 azumbres de aguas destiladas» a Ana Ruiz la Perona con la condición de que se los suministrase en pequeñas entregas a lo largo de los diez meses siguientes a la firma del contrato ${ }^{27}$. Celestina es el ejemplo litera-

25 FORBES, R.J. (1948), A Short History of the Art of Distillation, Leiden, Brill.

26 Sobre el ejercicio de la práctica destilatoria en la Castilla del siglo XVI ver REY BUENO, M. (2004b), El informe Valles: los desdibujados límites del arte de boticarios a finales del siglo XVI (1589-1594), Asclepio, 56 (2), pp. 243-268.

27 Archivo Histórico Provincial de Córdoba, Protocolos notariales, 14-35, 6, fol. 16r. Cita extraída de GARCía BALLESTER, L. (2001), La búsqueda de la salud. Sanadores y enfermos en la España medieval, Barcelona, Península, p. 634. García Ballester recoge, en esta su obra póstuma, las investigaciones llevadas a cabo por Ricardo Córdoba y Pilar Hernández, de la Facultad de Filosofía y Letras cordobesa, sobre la alimentación en la Córdoba de finales del 
rio más evidente, si bien existen otros casos reales dignos de ser tenidos en cuenta. Entre todos ellos, sobresale el laboratorio de María Sánchez de la Rosa, acusada de hechicera y procesada por la Inquisición en 1699. Doscientos años después de publicarse La Celestina comprobamos que son más las similitudes que las diferencias entre ambos laboratorios. María, como Celestina, disponía de gran número de pucheros, jarras vidriadas, ollitas y papeles con polvos, ungüentos y otros ingredientes que fueron minuciosamente detallados en el inventario que, por orden del tribunal del Santo Oficio madrileño, hizo el boticario Juan de Armuiña ${ }^{28}$.

No sólo eran hechiceras, según denominación inquisitorial, las expertas destiladoras de la Edad Moderna. El conocido como Libro del Prior, manual de técnica agrícola muy popular en la España del siglo XVII ${ }^{29}$, apunta también a las madres de familia como principales conocedoras de las prácticas destilatorias, con lo que además podían elaborar afeites y cosméticos.

Vemos, pues, cómo tras los seis oficios de Celestina se esconde todo un universo de conocimiento. Experta herbolaria y consumada destiladora, tan sólo nos hemos acercado al saber asociado al mundo vegetal, dejando en el tintero la experiencia que tenía en el mundo mineral, como lapidaria, o en conjunciones planetarias y estrellas, como astróloga judiciaria que es presentada por quienes bien la conocían.

siglo XV. Investigaciones que ponen de manifiesto el uso habitual en la vida cotidiana de aguas destiladas así como el empleo del alambique por particulares a quienes especieros y boticarios compraban el producto, estableciendo entre ellos auténticos contratos de suministro.

28 CiRAC ESTOPAÑán, S. (1942), Aportación a la historia de la inquisición española. Los procesos de hechicerías en la Inquisición de Castilla la Nueva (Tribunales de Toledo y Cuenca), Madrid, CSIC, pp. 43-46.

29 Obra de fray Miguel Agustín (1560-1630), prior de la Orden de San Juan de Jerusalén en Perpiñán, se publicó originalmente en catalán con el título de Llibre dels secrets de agricultura, casa rustica y pastoril. Recopilat de diversos autors, antichs y moderns, de llenguas llatina, italiana y francesa, en nostra vulgar llengua catalana (Barcelona, en la estampa de Esteve Liberôs, 1617), siendo traducido al castellano en 1625 y reeditado en más de una veintena de ocasiones entre 1625 y 1785 . A medio camino entre el libro de secretos y el manual técnico de agricultura, se trata de una copia casi literal de L'agriculture et maison rustique (París, 1570) escrita por el médico francés Charles Estienne y ampliada posteriormente por su yerno Jean Lièbaut, destacado espagirista y compilador de remedios secretos. 


\section{ANTECEDENTES Y METODOLOGÍA}

Dentro de los trabajos relacionados con plantas y animales en la Celestina, la obra ya citada de Laza Palacios ${ }^{30}$ incluye unas 60 especies de plantas medicinales, de ellas 55 del Acto 1, y un gran número de remedios extraídos de animales, aunque en dicho trabajo se comentan otras muchas más de las que en ningún momento habla La Celestina. Dichos animales, plantas y productos derivados, citadas en el glosario de Laza Palacios, que no aparecen en la obra, son las siguientes: alheñadas, brasil, canfora, sateriones y rábanos; o las cantáridas. Este autor no se interesa por vegetales que no estén relacionados con usos medicinales y mágicos, y por lo tanto no los cita. Martín-Aragón ${ }^{31}$ en su obra Los saberes médicos en La Celestina, que ha sido reimpreso en 1998 con ligeras correcciones, tiene una parte que trata sobre especies vegetales y animales. En el libro de Gómez ${ }^{32}$, se copian muchas datos de Laza Palacios, incluso también las plantas que no vienen citadas en la Celestina como si aparecieran realmente en la obra, lo que da lugar a equívocos. Otros trabajos que tratan de remedios y, como consecuencia, de plantas y animales son los de Botta ${ }^{33}$ y Cantalapiedra $^{34}$. Asimismo Castroviejo et al. ${ }^{35}$ escribieron sobre las plantas de la Celestina, aunque dejan de hablar de 26 especies que aquí comentamos.

El método seguido para la obtención de la información es la lectura y anotación de la obra, extrayendo todos los nombres vulgares referentes a plantas y animales, o a productos derivados de estos ${ }^{36}$. Después se ha asignado a cada uno un nombre científico. En general se ha considerado la especie más común en el caso de ciertos nombres que corresponden a denominaciones de género, como por ejemplo en la manzanilla, la mostaza o la madreselva. En otras ocasiones no se ha podido llegar de ninguna manera al nivel de especie, como es

30 LAZA PALACIOS (1958).

31 Martín-Aragón Adrada, F.J. (1998), Los saberes médicos en "La Celestina”, Diputación Provincial de Toledo (reimpresión del original de 1962).

32 Gómez, P. (2003), La rebotica de la Celestina. Antiguos remedios para las mujeres de hoy, Ediciones Mairi.

33 Botta, P. (1994), La magia en La Celestina, Cuadernos de Filología hispánica, 12, pp. 37-67.

34 Cantalapiedra, F. (2000), Floresta celestinesca, Reichenberger, Kassel Edition, pp. 855-1679.

35 Castroviejo, S. et al. (2000), Las plantas de la madre Celestina. En El Jardín de Melibea, Sociedad Estatal para la Conmemoración de los Centenarios de Felipe II y Carlos V, pp. 255-281.

36 De Rojas, F. (1977), La Celestina, Damiani, B.M (ed.), Madrid, Ediciones Cátedra. 
el caso del género Rosa sp., o para la trufa, que probablemente corresponderá al género Tuber, o del moho. Lo mismo ocurre para ciertos animales. Es el caso del dragón, la serpiente, el papagallo o el simio. Además se incluye el correspondiente comentario respecto a la asignación de la especie, en el caso de que esta sea discutible.

\section{RESULTADOS Y CONCLUSIONES}

En el presente trabajo se recogen todas las citas que se han encontrado en la obra, referentes a plantas y animales, y a nombres relacionados con estos, o a productos vegetales y animales. En los anexos 1 y 2 se detallan las plantas y animales respectivamente, ordenados por orden alfabético de géneros y especies, indicando en cada especie la familia botánica a la que pertenece en el caso de los vegetales, el acto en donde se encuentra la cita, la transcripción del texto en el que aparece esta, resaltado el nombre en cada caso con negrita. En algunos casos se añaden comentarios, explicando cómo se ha llegado a la determinación de los nombres científicos a partir del nombre común que aparece en la obra, en el caso de que haya duda sobre la identidad, y si han sido citados anteriormente por Laza.

Se citan en total en la obra 86 especies vegetales y 70 animales. De los vegetales, gran parte de las citas se refieren a usos medicinales, cosméticos y mágicos, aunque 25 especies aparecen en otro contexto, en sentido simbólico, como adorno y enriquecimiento del lenguaje, a veces dentro de dichos o en sentencias que recogen finísimas observaciones, otras veces en falsas creencias.

En el Acto $1^{\circ}$ son citadas 56 especies de vegetales y 29 de animales. Las otras 30 especies vegetales y 41 animales corresponden a la parte introductoria que lleva por título «El autor, excusándose», a los siguientes actos, hasta el último o número 21, o a la parte final que lleva por título «Concluye el autor».

Desde el punto de vista botánico, la familia con mayor número de especies es la de las leguminosas ( 9 especies), seguida de las compuestas, labiadas, gramíneas, rosáceas y rutáceas con 4 especies y después las liliáceas y malváceas con 3. Del total de especies, algo más de 50 son plantas oriundas de España y otras 30 son alóctonas o introducidas en tiempos históricos o se trata de productos vegetales importados de países lejanos. Dentro de estas se encuentran las relacionadas con los usados en cosmética, perfumería o como antisépticos, como incienso, mirra, ánime, benjuí, estoraque o algalia. Este último puede tratarse de un producto vegetal o animal. Con muchas de ellas se confeccionan bálsamos, término genérico que Laza no incluye en su glosa- 
rio, aunque es citado en el Acto 1 cuando dice que «y un poquillo de bálsamo tenía ella en una redomilla, que guardaba para aquel rascuño que tiene por las narices». Son mezclas de sustancias de naturaleza terpenoide u oleorresinas. El resto de las especies alóctonas son plantas que se cultivan en España, algunas desde muy antiguo. En la lista confeccionada no aparece ninguna planta americana, dada la proximidad en el tiempo del descubrimiento de América, lo que hizo imposible que alguna de las especies importadas del Nuevo Mundo se hubieran popularizado, a diferencia de lo que ocurre un siglo después en las obras de Cervantes. ${ }^{37}$

Los usos que aparecen (ver tabla 1) son en su mayoría para la salud de la piel, para baños o para el cuidado o tinción del pelo y para la elaboración de perfumes. También son importantes los usos relacionados con la higiene, salud y prevención de enfermedades y otros males del aparato genital femenino, y para remediar el mal de amores. Se citan textualmente, todos estos en el Acto 1: «aparejos para baños», para los que se emplean 14 especies diferentes; «aceites para el rostro» (15 especies), «aguas de rostro» (6 especies), «adelgazaba los cueros» o que afinaba el cutis ( 2 especies), «aguas para oler» (7 especies), perfumes (5 especies), «lejías para enrubiar» se entiende que el cabello (5 especies). Usa 4 especies para componer virgos: cola de caballo, fuste sanguino, hojaplasma y cebolla albarrana. Refiere que «esto de los virgos, unos hacía de vejiga y otros curaba de punto. Tenía un tabladillo, en una cajuela pintada, unas agujas delgadas de pellejero e hilos de seda encerados». Según Martín Aragón, es bastante improbable que la Celestina pudiera recomponer virgos con sus medios, aunque ello fuera de suma importancia, dada la mentalidad de la época. En una ocasión dice que pintaba en la palma letras, con azafrán, probablemente como sortilegio amoroso. En el Acto 7 indica que «Todo olor fuerte es bueno» para remediar el mal de la madre. En este caso cita 5 especies: ajenjo, incienso, poleo, romero y ruda. En el Acto 8 se refiere al diacitrón, o fruta de cidra confitada, como comestible, aparte de los productos alimenticios omnipresentes, el pan y el vino. En el Acto 10 se cita la trementina como remedio, aunque se advierte que es ardiente y hace sufrir al herido. Todas estas referencias anteriormente comentadas son estudiadas en la obra de Laza, al que por ejemplo se le pasa que la boca de dragón era utilizada como «antiveneno».

En sentido figurado se citan Narciso o Mirra, como personajes mitológicos. En dichos populares o a efectos comparativos se citan la col, la lechuga, el melón, el roble, las nueces, los algodones, las calabazas, la manzana, el

37 Ver nota 4, PARdo de SAnTAyAnA, et al. (2006). 
azahar, la ruda, la liga, el moho y las trufas. En algunos casos, ciertas expresiones utilizan con fuente las plantas; como en «estar embelesado».

En alusión directa, o sea como elementos del paisaje natural o humanizado, menciona los altos cipreses, los lirios o las azucenas, el mimbre o el álamo.

La mayoría de las plantas son citadas una vez, 13 han sido citadas dos veces, alguna de ellas con nombres diferentes. Los vegetales o productos vegetales que aparecen más veces en la obra son el trigo y la vid, 20 y 16 veces respectivamente. Sobre todo sus productos derivados, el pan y el vino, son elementos básicos en la alimentación, que no faltaban en la dieta dentro de nuestra cultura.

Otra mención que resulta interesante es la alusión a la sexualidad de los vegetales:

que el que verdaderamente ama es necesario que se turbe con la dulzura del soberano deleite, que por el hacedor de las cosas fue puesto, porque el linaje de los hombres se perpetuase sin lo cual perecería. Y no sólo en la humana especie, mas en los peces, en las bestias, en las aves, en las reptilias y en lo vegetativo, algunas plantas han este respecto, si sin interposición de otra cosa en poca distancia de tierra están puestas, en que hay determinación de herbolarios y agricultores, ser machos y hembras.

Se trata con dicha alusión a que hay plantas macho y hembra, o en tal caso a la presencia de flores masculinas y femeninas.

Referente al término yerba, Laza no recoge esta mención, que es genérica en el Acto 1: «Bien harás, y luego vamos, que no se debe dejar crecer la yerba entre los panes, ni la sospecha en los corazones de los amigos, sino limpiarla luego con el escardilla de las buenas obras». Sin duda se refiere a las malas hierbas, motivo de preocupación universal para los agricultores. Yerbas en plural aparece de nuevo en el Acto 5, en este caso en alusión directa y en el Acto 6. Otras muchas veces se refiere genéricamente, además de a yerbas, a «plantas», «árboles», «raíces», «pimpollo», «ramas», «ramos», «paja», «granzones», «hojas», «flores», «fruto», «grano», a veces «florida planta», «frescas hierbas» o a formaciones vegetales como «verdes prados» $\mathrm{o}$ «huerto florido».

Los animales son referidos en varias ocasiones para conseguir manteca, con fines cosméticos y medicinales, en total 18 especies, todas en el primer acto: "Y los untos y mantecas que tenía, es hastío de decir: de vaca, de oso, de caballos y de camellos, de culebra y de conejo, de ballena, de garza y de alcaraván y de gamo y de gato montés y de tejón, de arda, de erizo, de nutria». Como medicinal contra el mal de madre se usa el humo de plumas de perdiz. Como cosmético, en el Acto 1: «Adelgazaba los cueros con zumos de 
limones, con turbino, con tuétano de corzo y de garza, y otras confacciones». Para elaboración de perfumes: «Y en su casa hacía perfumes, falsaba estoraques, menjuí, ánimes, ámbar, algalia, polvillos, almizcles, mosquetes» (Acto 1). «Echaba de sí en bullendo un olor de almizque; yo hedía al estiércol que llevaba dentro de los zapatos» (Acto 19). El almizcle genuino procede de un género de rumiantes conocido como ciervo almizclero, según relata Laza ${ }^{38}$. Pero hay otras sustancias aromáticas de este tipo de diferentes orígenes. $\mathrm{O}$ el ambar gris, sustancia aromática que se obtiene del cachalote.

Si se tienen en cuenta los aspectos mágicos aplicados a remediar amores y «para se querer bien», en general se utilizan más remedios de origen animal, ${ }^{39}$ como «huesos de corazón de ciervo, lengua de víbora, cabezas de codornices, sesos de asno, tela de caballo, mantillo de niño, haba morisca, guija marina, soga del ahorcado, flor de hiedra, espina de erizo, pie de tejón, granos de helecho, la piedra del nido del águila, y otras mil cosas» (Acto 1). O cuando se refiere en el acto 3 a que «Entra en la cámara de los ungüentos y en la pelleja del gato negro donde te mandé meter los ojos de la loba, le hallarás, y baja la sangre del cabrón, y unas poquitas de las barbas que tu le cortaste». O «y hacia la mano derecha hallarás un papel escrito con sangre de murciélago debajo de aquel ala de dragón a que sacamos ayer las uñas».

Citas de plantas y animales para alimentación son: «Y enviaban sus escuderos y mozos a que me acompañasen, y apenas era llegada a mi casa cuando entraban por mi puerta muchos pollos y gallinas, anserones, anadones, perdices, tórtolas, perniles de tocino, tortas de trigo, lechones» (Acto 9).

Como es bien sabido la cetrería era práctica normal entonces, para caza y entretenimiento. Precisamente el motivo por el cual Calisto entró en la huerta de Melibea y la conoció fue para recuperar su halcón. Se citan tres nombres referentes a aves de cetrería: neblí, falcón o halcón y gerifalte.

Como era de esperar, los animales entran a formar parte de muchos dichos: «que aunque muda el pelo la raposa, su natural no despoja» (Acto 12). «Una golondrina no hace verano» (Acto 7). «Una perdiz sola por maravilla vuela» (Acto 7). O en versos improvisados: «Papagayos, ruiseñores / que cantais al alborada; / llevad nueva a mis amores / como espero aquí asentada» (Acto 19). «Saltos de gozo infinito / da el lobo viendo ganado; / con las tetas, los cabritos; / Melibea con su amado» (Acto 19). O sabias sentencias, que indican a veces agudas observaciones: «El falso boyzuelo con su blando cencerrear trae las perdices a la red» (Acto 10). «Las sucias moscas nunca pican sino los

38 Laza Palacios (1958), p. 95.

39 BotTA (1994), p. 60. 
bueyes magros y flacos; los gozques ladradores a los pobres peregrinos aquejan con mayor ímpetu». (Acto 12). «Pues las aves, ninguna cosa el gallo, come que no participe y llame las gallinas a comer de ello». (Acto 4). «Así como corderica mansa que mama su madre y la ajena» (Acto 11). "Como la sanguijuela saca la sangre, desagradecen, injurian, olvidan servicios, niegan galardón» (Acto 1). O «que es pensar sacar aradores a pala de azadón» (Acto 1), como el colmo de lo imposible.

Son de interés ciertas apreciaciones como las que indican que «Las cigüeñas mantienen otra tanto tiempo a sus padres viejos en el nido, cuanto ellos le dieron cebo siendo pollitos» (Acto 3). O que «El pelícano rompe el pecho por dar a sus hijos a comer de sus entrañas» (Acto 3). Símiles, como «Mi ronca voz de cisne» (Acto 19). «¡Como cola de alacrán!» (Acto 1). Además se citan dos casos de bestialidad: «¿No has leido lo de Pasife con el toro, lo de Minerva con el can?» (Acto 1). «Lo de tu abuela con el simio, ¿hablilla fue? Testigo es el cuchillo de tu abuelo» (Acto 1).

Cabe resaltar denominaciones antiguas de animales como mur para ratón, picaza para urraca o arda para ardilla.

Si atendemos al número de referencias de animales, los más citados son el caballo (11), asno (10), vaca, toro o buey (7); perro, can o gozque(6), gallo, gallina o pollo (6), perdiz (5), oveja, cordero o lechón (4), serpiente o culebra (3), víbora (3). Solamente 10 especies de las 70 referidas corresponden a animales domésticos, aunque estos son citados más frecuentemente. Sin embargo la gran cantidad de referencias a animales silvestres es reflejo de la importancia de la naturaleza silvestre en la vida diaria, hoy relegada al entretenimiento y goce.

Concluyendo, el autor, en boca de Pármeno en el acto primero y de Celestina, en múltiples ocasiones, demuestra tener buen conocimiento de los productos vegetales y animales utilizados por sanadoras o arregladoras de ciudad. La cita de 53 especies vegetales y de 29 animales, además de sus usos, solamente en el acto primero, da indicio del amplio conocimiento que se tenía sobre el tema. Las aplicaciones prácticas son especialmente prolijas en lo relativo a cosmética, perfumes, aclarado de pelo, baños, o en lo referente a restaurar virgos. Sin duda son reflejo de los conocimientos del autor, de ascendencia judía, que pese al tema tratado no tuvo ningún problema para la publicación de su obra. Si sus conocimientos sobre el tema fueron más amplios, las exigencias de la obra estaban bien servidas con lo que ya se explicitaba. Es interesante el caso de muchas de las plantas utilizadas para baños, como por ejemplo el culantrillo, de las que ahora no hay noticia de que se sigan utilizando. La adición al agua de baño de gran variedad de plantas sería 
además necesaria, si se tiene en cuenta que la calidad del agua desde el punto de vista higiénico en tiempos pasados era muy deficiente.

La obra está llena de interesantes observaciones con relación al comportamiento animal, y aparte de los animales utilizados como medicinales, cosméticos, o para perfume, se encuentran los más habituales en alimentación. El asno y el caballo son los animales más citados, seguido del perro, toro o vaca y gallo o gallina; después la perdiz, animal silvestre frente a los anteriores, que son todos domésticos. Algunas de las citas se refieren a dichos y para establecer similitudes.

En este análisis, realizado dentro de nuestro ámbito de conocimiento, se puede percibir la concepción que se tenía en aquella época del mundo vegetal y animal. Todos estos conocimientos se relacionaban en general con la obtención de recursos vitales, como alimento o medicinas. También formaban parte del lenguaje, dada su presencia en giros y figuras literarias. Dentro de un ámbito urbano, las aplicaciones prácticas eran primordiales, sobre todo en lo relativo al cuidado del cuerpo y a ciertas actuaciones mágicas, con fines amorosos. Además los datos obtenidos referentes a especies vegetales y animales se pueden comparar con otras floras y faunas literarias de épocas más o menos próximas en el tiempo. Estos análisis comparativos permitirían ver la variación en la concepción del mundo natural, tanto vegetal como animal en las diferentes épocas, así como la pervivencia de ciertos conocimientos. De cualquier manera son una muestra de la concepción de la naturaleza hace 500 años. 


\section{ANEXO 1. ESPECIES VEGETALES}

Se indican al final con un asterisco las especies que cita Laza y la página en que es citada entre paréntesis. En las citas largas, para no repetir, se ponen puntos suspensivos y se refiere a la especie en donde se encuentra la cita completa.

Abelmoschus moschatus Medik. MALVACEAE

Acto 1: «Y en su casa hacía perfumes, falsaba estoraques, menjuí, ánimes, ámbar, algalia, polvillos, almizcles, mosquetes».

Otra algalia de origen vegetal, además de la que procede del animal llamado civeta (ver Viverra civeta), es usada en perfumería por sus semillas o granos de algalia, también de olor almizclado. ${ }^{40}$ Es la especie conocida también como abelmosco. Procede del sur de Asia.

\section{Adiantum capillus-veneris L. ADIANTACEAE}

Acto 1: «Aparejos para baños, esto es una maravilla, de las hierbas y raíces que tenía en el techo de su casa colgadas: manzanilla y romero, malvaviscos, culantrillo, coronillas, flor de saúco y de mostaza, espliego y laurel blanco, tortarosa y gramonilla, flor salvaje e higueruela, pico de oro y hoja tinta».

La utilización que aparece en la Celestina es como una hierba que era añadida a agua de baños. Esos baños no eran simplemente higiénicos, sino que se tomaban por su acción curativa, lo que no contradice que la Celestina además pudiera conocer la acción emenagoga de esta planta, que es su uso medicinal más frecuente. *(122).

\section{Alchemilla vulgaris L. ROSACEAE}

Acto 1: «Aparejos para baños...flor salvaje...» (ver Adiantum capillus-veneris)

Laza recogió este nombre de una hechicera andaluza de la zona de Despeñaperros, que así llamaba a esta especie. Según Laguna ${ }^{41}$ tenía múltiples aplicaciones medicinales, sobre todo por su acción astringente, lo que es corroborado por Font Quer ${ }^{42}$. Sin duda ese efecto puede ser beneficioso para la piel. *(181).

\section{Allium ampeloprasum L. LILIACEAE}

Acto 1: «iMaldito sea este necio; y qué porradas dice!

Acto 1: «Señor, Sempronio y una puta vieja alcoholada daban aquellas porradas».

Aunque se refiere a necedades, el nombre proviene de la planta, el ajo porro o puerro silvestre, antecesor del puerro cultivado.

40 Del Valle Nieto, A. (2002), Botica y Farmacia en el Quijote, Anales de la Real Academia Nacional de Farmacia, 68 (4), pp. 23-67.

41 Laguna, A. (1991), Pedacio Dioscorides Anazarbeo, Acerca de la materia medicinal $y$ de los venenos mortíferos. Traducido del griego e ilustrado por el Doctor Andrés de Lagu$n a$, ed. facs., Madrid, Consejería de Agricultura y Cooperación de la CAM. bor.

42 FonT Quer, P. (1961), Plantas medicinales. El Dioscórides renovado, Barcelona, La- 
Anthoxanthum odoratum L. POACEAE

Acto 1: «Aparejos para baños...gramonilla...» (ver Adiantum capillus-veneris)

Pudiera tratarse de la grama de olor, que impregna de aroma al heno cortado por su contenido en cumarina, que comienza a oler sobre todo cuando la hierba está seca. Aunque también podría ser gramonica, que corresponde a Agrimonia eupatoria L. *(181).

\section{Antirrhinum majus L. SCROPHULARIACEAE}

Acto 10: «no de otra manera que, cuando vio en sueños aquel grande Alejandre, rey de Macedonia, en la boca del dragón la saludable raíz con que sanó a su criado Tolomeo del bocado de la víbora».

No parece ser una planta medicinal con gran tradición en la Península Ibérica. ${ }^{43}$. Aquí se refiere claramente al uso de su raíz como contraveneno ante la picadura de víbora, tomado de un clásico, por lo que no tiene por qué reflejar usos de la época.

\section{Althaea officinalis L. MALVACEAE}

Acto 1: «Aparejos para baños...malvaviscos...» (ver Adiantum capillus-veneris)

Es planta medicinal por excelencia. Debido a su contenido en mucílagos, se ha empleado como suavizante de las mucosas. Por ello también debe ser indicada para baños. ${ }^{*}(155)$.

\section{Achillea millefolium L. ASTERACEAE}

Acto 1: «hacía lejías para enrubiar, de sarmientos, de carrasca, de centeno, de marrubios, con salitre, con alumbre y millifolia y otras diversas cosas».

Se usa popularmente como tónica y por su efecto astringente, que es por lo que se utilizaría como antihemorrágica en menstruaciones excesivas. Aquí se cita exclusivamente para decolorar (enrubiar), probablemente el pelo. $*(158)$.

\section{Artemisia absinthium L. ASTERACEAE}

Acto 7: «Todo olor fuerte es bueno, así como poleo, ruda, ajiensos, humo de plumas de perdiz, de romero, de moxquete, de incienso».

La especie más frecuentemente utilizada es la que se cita en la cabecera. Se usa tradicionalmente como tónico, febrífugo y emenagogo; el último de los usos parece ser el que corresponde a esta cita. Celestina alude a su olor fuerte y característico, junto con el de otras plantas. El ajenjo tiene un componente tóxico en su aceite esencial, la tuyona, que produce intoxicación por acumulación. De ahí que el licor de absenta produjera graves intoxicaciones, cuando se puso de moda en Francia, después de la célebre revolución. El vermut también se hace con esta planta, que es rica en amargos. Wermut es el nombre popular alemán de esta especie. *(104).

\section{Asphodelus albus L. LILIACEAE}

Acto 1: «hacía solimán, afeite cocido, argentadas, bujelladas, cerillas, lanillas, unturillas, lustres, lucentores, clarimientos, albalinos, y otras aguas de rostro, de rasuras de gamones, de cortezas de espantalobos, de teraguncia, de hieles de agraz, de mosto, destilados y azucarados».

Sin duda se trata de raspaduras de las raíces de esta planta. La especie más común es la que se considera aquí. Laza, en la entrada GAMONES (RASURAS DE), no aclara la parte de la planta que se utiliza, lo que quizá ha llevado a Gómez (2003: 118) a considerar que eran las hojas las que se aplicaban directamente al rostro. Aunque después este mismo autor explica el significado de rasura, en LICOR DE LAS RASURAS, lo que aclara que eran las raíces tuberosas la parte utiliza-

\footnotetext{
43 FONT QUER (1961), p. 608.
} 
da. Precisamente esta segunda expresión no procede de La Celestina, sino de la obra de Rodrigo de Cota «Diálogo entre el amor y un viejo»*(135).

\section{Athyrium filix-femina (L.) Roth ATHYRIACEAE}

Acto 1: «Y en otro apartado tenía para remediar amores y para se querer bien. Tenía huesos de corazón de ciervo, lengua de víbora, cabezas de codornices, sesos de asno, tela de caballo, mantillo de niño, haba morisca, guija marina, soga del ahorcado, flor de hiedra, espina de erizo, pie de tejón, granos de helecho, la piedra del nido del águila, y otras mil cosas».

Los granos de helecho pueden ser los esporangios de esta especie o también los de Dryopteris filix-mas (L.) Schott u Osmunda regalis L. Todos los remedios aquí referidos, vegetales, animales y minerales, eran usados para sortilegios amorosos. *(136).

\section{Boswellia sacra Flueckiger BURSERACEAE}

Acto 7: «Todo olor fuerte es bueno, así como...de incienso» (ver Artemisia absinthium).

Se trata de un árbol que vive en África oriental y Arabia, y del que se saca la resina mediante cortes en su corteza. Esta se solidifica rápidamente. Se quema para purificar y como ofrenda a Dios. Es muy utilizada en la liturgia de la iglesia católica. Efectivamente, los compuestos volátiles que se producen cuando se quema, son desinfectantes. *(124).

\section{Brassica nigra (L.) Koch BRASSICACEAE}

Acto 1: «Aparejos para baños...mostaza...» (ver Adiantum capillus-veneris).

Hay dos especies de mostaza: la blanca o Sinapis alba L. y la negra, que es la que se ha considerado. Ambas, por las propiedades rubefacientes de los principios activos que contienen, sobre todo glucosinolatos, han sido utilizadas para calentar por vía externa o interna, cuando el frío se ha apoderado del cuerpo o de ciertas partes y se produce la enfermedad. Además reaviva instintos languidecientes, o sea, que tiene propiedades afrodisíacas. $*(162)$.

\section{Brassica oleracea L. BRASSICACEAE}

Acto 6: «Tu dirás lo tuyo: entre col y col, lechuga».

El autor la cita en un dicho popular, que parece indicar que las cosas son como han de ser.

\section{Buxus sempervirens L. BUXACEAE}

Acto 1: «hacía solimán,...bujelladas...» (ver Asphodelus albus).

Laza indica que podría provenir de bujeta o vaso pequeño que se hace con madera de boj, para que contenga sustancias aromáticas. El boj se plantaba en todos los claustros de los monasterios y en jardines para disponer de su madera, dura, muy consistente y amarilla, con la que se confeccionaban pequeñas herramientas, cucharas y tenedores. Todo parece indicar que bujelladas eran «confacciones» basadas en esta planta.*(108).

\section{Cercis siliquastrum L. FABACEAE}

Acto 1: «Aparejos para baños pico de oro...» (ver Adiantum capillus-veneris).

Martín-Aragón ${ }^{44}$ entiende que pudiera tratarse de esta especie. Pico de oro sería una deformación de pica moro, que es como se llama a esta especie en ciertos pueblos de Guadalajara, en Sayatón y Bolarque, según indica Máximo Laguna ${ }^{45}$ en su Flora forestal española. *(166).

44 MARTÍN-ARAGÓN (1998), p. 91.

45 Laguna, M. (1890), Flora forestal española, Madrid, Imprenta del Colegio Nacional de Sordo-Mudos y de Ciegos. 
Citrus aurantium L. RUTACEAE

Acto 1: «Sacaba aguas para oler de rosas, de azahar, de jazmín, de trébol, de madreselva; y clavellinas, mosquetadas y almizcladas, polvorizadas con vino»;

Acto 19: «Tenía unas manos como la nieve, que cuando las sacaba de rato en rato de un guante, parecía que se derramaba azahar por casa».

El azahar es la flor del naranjo, árbol ornamental traído a España por los árabes, y que se encontraba en los patios de las mezquitas, antes que llegara el naranjo dulce en el siglo XV a través de Portugal ${ }^{46}$. El agua de azahar se ha utilizado desde antiguo. Es difícil definir este olor tan conocido, penetrante, algo dulce y que agrada a todos los gustos. Es aroma que se utiliza en perfumería. $*(102)$.

Citrus limon (L.) Burm. fil. RUTACEAE

Acto 1: «Adelgazaba los cueros con zumos de limones, con turbino, con tuétano de corzo y de garza, y otras confacciones».

Acto 1: «Los aceites que sacaba para el rostro no es cosa de creer: de estoraque y de jazmín, de limón, de pepitas, de violetas, de menjuí, de alfócigos, de piñones, de granillo, de azofeifas, de neguilla, de altramuces, de arvejas y de carillas y de hierba pajarera»;

Laguna ${ }^{47}$ cita que el zumo de limón quita los barros y cualesquiera manchas del rostro. *(153).

\section{Citrus medica L. RUTACEAE}

Acto 8: «Dije, señor, a Pármeno, que fuese por una tajada de diacitrón».

Acto 8: «Allá irás con el diablo tu y malos años; y en tal hora comieses el diacitrón, como Apuleyo el veneno que le convirtió en asno».

Acitrón o diacitrón es la cidra confitada, aunque el diccionario de la RAE indica que es la fruta llamada cidra después de confitada; pero ninguno de los dos aclara de qué especie se trata. La cidra es el primer cítrico conocido en la región mediterránea. Su epíteto específico alude a los persas de la región de Media, a través de los cuales se introdujo probablemente en tiempos de Alejandro Magno en el ámbito mediterráneo, en donde ya se conocía en tiempos de los romanos. Actualmente, en que este fruto prácticamente ha desaparecido o es muy raro, la especie Cucurbita ficifolia $\mathrm{C}$. D. Bouché, americana, es la más utilizada en confitería para hacer dulces de los que se denominan, en la actualidad, de cidra. *(87),

\section{Colutea arborescens L. FABACEAE}

Acto 1: «hacía solimán,...espantalobos...» (ver Asphodelus albus).

La utilización de la corteza de esta planta en cosmética es una novedad aportada por la Celestina. Las semillas eran consideradas tradicionalmente purgantes y eméticas, aunque, al parecer, era poco utilizada ${ }^{48} \cdot *(128)$.

\section{Commiphora abyssinica Engl. BURSERACEAE}

Acto 16: «Y aún otras, de mayores fuegos encendidas, cometieron nefarios e incestuosos yerros, como Mirra con su padre».

Aunque no se refiere a la planta, sino a la hija que mantuvo relaciones incestuosas con su padre Theais, rey de Siria, que habiéndose enamorado de él, aprovechando la noche, satisfizo su pasión,

46 RAMÓN-LACA, L. (2003), The introduction of cultivated Citrus to Europe via Northern Africa and the Iberian Peninsula, Economic Botany, 57 (4), pp. 502-514.

47 LAGUNA (1555), Libro 1, Cap. 63.

48 FONT QUER (1962), p. 376. 
según la mitología griega narrada por Ovidio. Entonces los dioses la convirtieron en el árbol del que se obtiene esta resina aromática. Es planta oriunda de Arabia y Etiopía. Laguna ${ }^{49}$ hace una cita expresa de La Celestina: «No topo Celestina con este azeyte, con quanto fue lapidaria». *(158).

\section{Cornus sanguinea $\mathrm{L}$. CORNACEAE}

Acto 1: «Tenía en un tabladillo, en una cajuela pintada, una agujas delgadas de pellejeros e hilos de seda encerados, y colgadas allí raíces de hojaplasma y fuste sanguino, cebolla albarrana y cepacaballo; hacía con esto maravillas: que, cuando vino por aquí el embajador francés, tres veces vendió por virgen una criada que tenía».

Con la raíz del fuste sanguino se refiere probablemente al cornejo o sanguino. La Celestina lo utilizaba como cicatrizante cuando reponía virgos, según parece indicar. Las hojas de esta planta contienen ácido salicílico y sus semillas aceite. La corteza se ha utilizado como febrífuga. ${ }^{*}(170)$.

\section{Crocus sativus L. IRIDACEAE}

Acto 1: «a otros pintaba en la palma letras con azafrán»;

Se alude sin duda a una práctica mágica. Como es bien sabido, el azafrán se utiliza como colorante alimentario, además de como saborizante. Se usa también contra el mareo. *(102).

\section{Cucumis melo L. CUCURBITACEAE}

Acto 18: «Que los caxquetes de Almacén así los corta como si fuesen hechos de melón».

Se refiere a la facilidad con que se cortan las rajas de melón.

\section{Cupressus sempervirens L. CUPRESSACEAE}

Acto 19: «Escucha los altos cipreses, cómo se dan paz unos ramos con otros por intercesión de un templadico viento que los menea».

Especie presente en todo el ámbito mediterráneo desde antiguo, aunque su lugar de origen es la región este de la cuenca mediterránea, incluida la isla de Chipre, de donde le viene el nombre. Resulta un árbol emblemático por su silueta característica.

\section{Daphne gnidium L. THYMELAEACEAE}

Acto 1: «Aparejos para baños tortarosa...» (ver Adiantum capillus-veneris).

Cantalapiedra (2000) considera que la tortarosa podría corresponder al torvisco, según los diccionarios de Autoridades y de la RAE. *(181)

\section{Dianthus plumarius L. CARYOPHYLLACEAE}

Acto 1: «Sacaba aguas para oler de...clavellinas...» (ver Citrus aurantium).

El uso actual de esta planta es exclusivamente ornamental. Pero como ha ocurrido con otras muchas especies que ahora se tienen como meramente ornamentales, en épocas pasadas se cultivaban porque eran medicinales. Se ha olvidado el uso, pero se siguen cultivando. *(117).

\section{Dracunculus vulgaris Schott ARACEAE}

Acto 1: «hacía solimán,...teraguncia...» (ver Asphodelus albus).

La taraguntia o taragontia es una deformación de dragontea a través de zaragutia. El uso que da la Celestina a esta planta es el cosmético, para aguas de rostro, para lo que se utilizaba el jugo de su raíz. Es una especie considerada desde antiguo como contraveneno para las picaduras de serpiente. Su rizoma hecho pasta se utilizaba como callicida. Se trata de una especie que se cultivaba como

\section{LAGUNA (1555).}


medicinal en monasterios y jardines. En la actualidad se encuentra raramente en España, como planta asilvestrada. ${ }^{*}(181)$.

\section{Equisetum arvense L. EQUISETACEAE}

Acto 1: «Tenía en un tabladillo...cepacaballo...» (ver en Cornus sanguinea).

Con cepacaballo probablemente se refiera a esta especie de cola de caballo, que es la más frecuente, o a E. hyemale L. También está registrado este nombre para Xanthium spinosum L., aunque las propiedades hemostáticas de los equisetos refuerzan la primera opinión. *(114).

\section{Ficus carica L. MORACEAE}

Acto 9: «Por una vez que haya de salir donde pueda ser vista, enviste su cara con hiel y miel, con uvas tostadas y higos pasados, y con otras cosas, que por reverencia de la mesa dejo de decir».

En este caso los higos se utilizan como mascarilla para el cutis de la cara.

\section{Gossypium herbaceum L. MALVACEAE}

Acto 10: «para tus oídos unos algodones de sufrimiento y paciencia»,

Esta planta es citada en sentido figurado, como protector ante el sufrimiento, dada su blandura y suavidad. El algodón es la fibra que recubre a las semillas dentro del fruto de esta planta.

\section{Hedera helix L. ARALIACEAE}

Acto 1: «Y en otro apartado tenía para remediar amores...hiedra...» (ver Athyrium filix-femina).

La hiedra tiene propiedades mágicas. En la Antigüedad era empleada para realizar sortilegios de amor y fidelidad, para protegerse contra la negatividad y para invocar a los espíritus. Es planta que tuvo usos medicinales en tiempos pasados. Florece en otoño y sus frutos son venenosos, porque contienen hederina, un glucósido tóxico, que se utiliza como desinfectante de úlceras. Con frecuencia se cultiva como ornamental otra especie de hojas mayores y más brillantes. Se trata de H. maroccana McAllister. *(189).

\section{Hypericum androsaemum L. HYPERICACEAE}

Acto 1: «Tenía en un tabladillo...hojaplasma...» (ver Cornus sanguinea).

Laza recogió este nombre, inédito hasta ahora, en los montes cercanos a Ávila en junio de 1944. Es más conocida con nombres como toda-buena o todosana. Tiene propiedades cicatrizantes, y se toma para abrir el apetito. $50 *(143)$.

\section{Ipomoea turpethum R. Brown CONVOLVULACEAE}

Acto 1: «Adelgazaba los cueros con...turbino...» (ver Citrus limon).

El turbit genuino ya se falsificaba en el siglo XVI con la raíz de Thapsia villosa L., conocida como turbit falso ${ }^{51}$, tomado de Cienfuegos ${ }^{52}$, especie que crece en España, y que se vendía incluso por turbit en Alejandría, por lo que tampoco se debería descartar a esta especie como el turbino aquí indicado. Laza identifica el turbit con Globularia alypum, que se trataría del turbit blanco, del que se utilizaban las hojas como purgantes. La novedad en La Celestina sería el uso del turbit en cosmética para afinar el cutis o la piel en general, en lugar de como purgante. Según el diccionario de la RAE, el turbino es la raíz del turbit pulverizada. *(185).

\footnotetext{
50 FONT QUER (1961), p. 143.

51 FONT QUER (1961).

52 Cienfuegos (alrededor de 1620), ver nota 21.
} 


\section{Iris germanica L. IRIDACEAE}

Acto 19: «Vistanse nuevas colores / los lirios y la azucena»;

Planta cultivada desde antiguo como ornamental y medicinal.

\section{Jasminum officinale L. OLEACEAE}

Acto 1: «Sacaba aguas para oler de...jazmín...» (ver Citrus aurantium).

Acto 1: «Los aceites que sacaba para el rostro...jazmín...» (ver Citrus limon).

El aroma de jazmín se utiliza desde antiguo en todo el ámbito mediterráneo. *(147).

\section{Juglans regia L. JUGLANDACEAE}

Acto 9: «Hija, de estos dolorcillos tales, más es el ruido que las nueces».

Este árbol se cultiva en toda la Península Ibérica desde tiempo inmemorial para conseguir madera, sustancias colorantes y por sus apreciados frutos. También se utiliza como medicinal. En este caso la cita es en sentido figurado.

\section{Lactuca sativa $\mathrm{L}$. ASTERACEAE}

Acto 6: «Tu dirás lo tuyo: entre col y col, lechuga».

El autor la cita en un dicho popular, que parece indicar que las cosas son como han de ser.

\section{Lagenaria siceraria L. CUCURBITACEAE}

Acto 1: «Los aceites que sacaba para el rostro...pepitas..». (ver Citrus limon).

Acto 9: «Que así goce de mi, unas tetas tiene, para ser doncella, como si tres veces hobiese parido; no parecen sino dos grandes calabazas»».

Laza considera que se trata de las semillas de Cucurbita pepo L., lo que probablemente es erróneo, dado que esta especie fue traída de América. Al menos parece muy corto el tiempo desde 1492, para que ya en 1499 o antes, mientras escribía la obra el autor, se hubiera extendido su cultivo y su uso. Por ello pensamos que el autor se refiere a la calabaza del Viejo Mundo, la calabaza vinatera, empleada desde antiguo para hacer recipientes, o cortada por la mitad como escudillas. Es también la calabaza de peregrino. De sus pepitas se puede obtener aceite, que era lo que se utilizaba para la cara. La segunda cita es en sentido figurado. $*(165)$.

\section{Laurus nobilis L. LAURACEAE}

Prólogo: «Hallé esta sentencia corroborada por aquel gran orador y poeta laureado, Francisco Petrarca»

Acto 1: «Aparejos para baños...laurel blanco...» (ver Adiantum capillus-veneris).

La denominación laurel blanco debe referirse al laurel común, ya que este nombre no aparece registrado para ninguna otra especie. ${ }^{*}(148)$.

\section{Lavandula latifolia Medicus LAMIACEAE}

Acto 1: «Aparejos para baños...espliego...» (ver Adiantum capillus-veneris).

El espliego o alhucema es planta conocida y utilizada de antiguo para baños, por su fragante aroma, que ahora se llama de lavanda. Precisamente la etimología de este término está relacionada con los baños. *(129).

\section{Lilium candidum L. LILIACEAE}

Acto 19: «Vistanse nuevas colores / los lirios y la azucena»;

Se trata de una de las plantas cultivadas más antiguas de que se tiene noticia. 
Lonicera periclymenum L. CAPRIFOLIACEAE

Acto 1: «Sacaba aguas para oler de....madreselva...» (ver Citrus aurantium).

Planta trepadora de flores muy olorosas, de la que se obtenía aguas de baño o colonia. Sus frutos son tóxicos. *(154).

Lupinus albus L. FABACEAE

Acto 1: «Los aceites que sacaba para el rostro...altramuces...» (ver Citrus limon).

El altramuz es planta cultivada y asilvestrada desde antiguo en España. Aquí se cita para la elaboración de cosméticos para la cara. Según relata Laguna ${ }^{53}$, esta planta purifica el rostro. $*(95)$.

\section{Malus domestica Borkh. ROSACEAE}

Acto 6: «Si ella se hallara presente en aquel debate de la manzana con las tres diosas, nunca sobrenombre de discordia le pusieran».

Acto 6: «Así que llamará manzana de concordia».

Citada en sentido figurado en estas dos ocasiones.

\section{Marrubium vulgare L. LAMIACEAE}

Acto 1: «hacía lejias para enrubiar, de sarmientos, de carrasca, de centeno, de marrubios, con salitre, con alumbre y millifolia y otras diversas cosas».

Esta especie tiene propiedades antitérmicas, se usa para afecciones bronquiales, ayuda en partos difíciles y es emenagoga. Sin embargo, la Celestina utilizaba el marrubio como tintórea. *(157).

\section{Matricaria recutita L. ASTERACEAE}

Acto 1: «Aparejos para baños...manzanilla...» (ver Adiantum capillus-veneris).

La manzanilla más común, que se encuentra cultivada en muchos lugares de España, es la especie arriba indicada. La otra manzanilla de uso más frecuente en el norte de España es la amarga o Chamaemelum nobile (L.) All. ${ }^{54}$. El autor considera que es una buena planta para baños. *(156).

\section{Melilotus officinalis (L.) Pallas FABACEAE}

Acto 1: «Sacaba aguas para oler de...trébol...» (ver Citrus aurantium).

Acto 1: «Aparejos para baños...coronillas...» (ver Adiantum capillus-veneris).

Laza, basándose principalmente en los usos, aguas para oler y aparejos para baños, interpreta que debe tratarse del trébol oloroso, y sin dudar afirma, que se trata de esta especie, vulgarmente conocida por los nombres de coronillas, trébol oloroso o meliloto. Efectivamente esta planta contiene cumarinas, que son sustancias con aroma penetrante. A pesar de la opinión de Laza, parece extraño que dos nombres vulgares distintos, trébol y coronillas, citados tan próximos entre sí, apenas 10 líneas de diferencia, correspondan a la misma especie. Sin embargo, de momento no se encuentra otra solución a la identificación del trébol oloroso. *(121, 184).

\section{Mentha pulegium L. LAMIACEAE}

Acto 7: «Todo olor fuerte es bueno, así como poleo...» (ver Artemisia absinthium).

El poleo corresponde sobre todo a esta especie, pero a otras mentas ibéricas, Mentha cervina L. y M. longifolia (L.) Hudson, también se les denomina poleos. Efectivamente, su olor es inconfundible. $*(169)$.

53 LAGUNA (1555).

54 Pardo de Santayana, M. y Morales, R. (2006), Manzanillas ibéricas: historia y usos tradicionales, Revista de Fitoterapia, 6 (2), pp. 143-153. 


\section{MUSGO}

Acto 15: «piedra movediza que nunca moho la cobija».

Con «moho» se refiere probablemente a alguna especie de musgo o de liquen, que es incapaz de crecer en las piedras de pedreras móviles, que aún no están asentadas. Martínez Abaigar y Nuñez Olivera ${ }^{55}$, en su trabajo sobre la fiesta tradicional, comentan estas denominaciones.

\section{Narcissus pseudonarcissus L. AMARYLLIDACEAE}

Acto 4: «Por fe tengo que no era tan hermoso aquel gentil Narciso, que se enamoró de su propia figura, cuando se vido en las aguas de la fuente».

Es conocido el mito griego de Narciso, que se convirtió en la flor que lleva su nombre. Por lo tanto el nombre se lo dio el personaje a la planta. La especie considerada es la más característica, y además es la originaria de muchas variedades de cultivo. Este género alcanza una gran diversidad en la Península Ibérica, de donde se recolectaron casi todas las especies silvestres, que debidamente seleccionadas e hibridadas han dado lugar a todas las estirpes cultivadas.

\section{Nigella sativa L. RANUNCULACEAE}

Acto 1: «Los aceites que sacaba para el rostro...neguilla...» (ver Citrus limon).

Otra especie llamada neguilla es Agrostemma githago L., aunque comparte con las anteriores sólo el aspecto de sus semillas. Esta semejanza debe ser el motivo de que, en los escritos antiguos, se hayan confundido y sean denominadas con el mismo nombre vulgar. El vinagre de neguilla se ha utilizado para quitar manchas y asperezas de la piel, y contra el dolor de muelas, porque al parecer tiene efectos calmantes. Aquí se cita como cosmético facial. *(163).

\section{Olea europaea L. OLEACEAE}

Acto 3: «a los chirriadores quicios de las puertas hacen con aceites usar su oficio sin ruido».

Acto 3: «baja acá el bote del aceite serpentino»

Acto 3: «por la áspera ponzoña de las víboras de que este aceite fue hecho»

Acto 5: «iOh serpentino aceite!»

El aceite de oliva era utilizado como excipiente para hacer el serpentino que se cita arriba que era de uso muy propio para hechizos y encantos amorosos. Laguna ${ }^{56}$ indica que «el aceite desencoge y extiende los encogidos y retirados nervios, y dan gran refrigerio y desencanto a los miembros muy fatigados, y los hace más diestros». *(102).

\section{Pinus pinaster L. PINACEAE}

Acto 10: «Señora, no tengas por nuevo ser más fuerte de sufrir al herido la ardiente trementina y los ásperos puntos que lastiman lo llagado, doblan la pasión, que no la primera lisión, que dio sobre sano».

La trementina o aguarrás se obtenía casi siempre de la resina del pino resinero, y era utilizada en medicina, además de como disolvente. Las friegas con este producto producen rubefacción y curan por el intenso calor que genera. Por eso se refiere en el texto a la ardiente trementina. *(165).

\section{Pinus pinea L. PINACEAE}

Acto 1: «Los aceites que sacaba para el rostro...piñones...» (ver Citrus limon).

El pino piñonero es el que produce piñones, de los que al parecer Celestina obtenía aceite para

55 Martínez Abaigar, J. y Nuñez Olivera, E. (2001), The legend and procession of the Moss Men from Béjar (Salamanca, Spain), Journal of Bryology, 23, pp. 264-266.

56 LaGuna (1555), p. 34. 
la cara. Como otras muchas semillas, el piñón contiene alrededor de un $50 \%$ de aceite y casi $40 \%$ de proteína. $*(168)$.

\section{Pistacia vera L. ANACARDIACEAE}

Acto 1: «Los aceites que sacaba para el rostro....alfócigos...» (ver Citrus limon).

El pistacho era considerado afrodisíaco. Al parecer su cultivo en España en tiempos pasados fue relativamente frecuente. El alfónsigo o pistacho produce un agradable fruto seco comestible, aunque aquí Celestina lo cita por su aceite, abundante en las semillas, que se debía utilizar entonces para cosmética. $*(93)$.

\section{Plumbago europaea L. PLUMBAGINACEAE}

Acto 15: «Que estoy embelesada, sin tiento, como quien cosa imposible oye».

La belesa es la planta que presta su nombre a la acción de «embelesar», porque se ha utilizado para adormecer a los peces en remansos de ríos y pescarlos sin trabajo. Su principio tóxico es la plumbagina, una naftoquinona, que tiene efectos vesicantes y abortivos, y que además se ha utilizado para el tratamiento de eczemas y psoriasis. En el siglo XV puede que se utilizara además para «embelesar» no solo a los peces, sino también a insectos como las pulgas en los establos, uso que ha perdurado hasta comienzos del siglo XX en La Mancha.

\section{Psoralea bituminosa L. FABACEAE}

Acto 1: «Aparejos para baños...higueruela...» (ver Adiantum capillus-veneris).

La higueruela, también llamada trébol hediondo, por su olor bituminoso, sería utilizada probablemente por su acción antiséptica para los baños. *(143).

\section{Quercus ilex L. FAGACEAE}

Acto 1: «hacía lejias para enrubiar, de sarmientos, de carrasca, de centeno, de marrubios, con salitre, con alumbre y millifolia y otras diversas cosas».

Según Laza se trataría de la coscoja o maraña, $Q$. coccifera L., probablemente basado en la presencia de unas agallas de color carmín, que Laguna ${ }^{57}$ denomina «pelotillas bermejas» y que se han utilizado para teñir. Era la grana que se obtenía de dichas agallas, producidas por el coccus (de ahí su nombre específico de coccifera), en árabe quermes, de donde viene el nombre del color carmesí. Sin embargo es más frecuente llamar con el nombre de carrasca a las formas achaparradas de encina. La corteza de esta especie y de otras del género Quercus se ha utilizado de siempre para curtir cueros y para teñir. La coscoja es menos utilizada en general, porque es mucho menos frecuente. $*(111)$.

\section{Quercus robur L. FAGACEAE}

Acto 8: «Un solo golpe no derriba un roble».

Se trata de un dicho que ha perdurado a través de los siglos, y que hace alusión a la fortaleza de este árbol.

\section{Rosa sp. ROSACEAE}

El autor, excusándose: «Y encima de rosas, sembrar mil abrojos»

Acto 1: «Sacaba aguas para oler de rosas...» (ver Citrus aurantium).

El agua de rosas es utilizada por su agradable aroma en farmacia, perfumería, cosmética y cocina. $*(172)$.

\section{LAGUNA (1555).}


Rosa moschata Herm. ROSACEAE

Acto 1: «Y en su casa hacía perfumes, falsaba...mosquetes» (ver Abelmoschus moschatus)

Acto 1: «Sacaba aguas para oler...mosquetadas...» (ver Citrus aurantium).

Acto 7: «Todo olor fuerte es bueno, así como de...moxquete...» (ver Artemisia absinthium).

El término mosquetes no se encuentra aclarado en ninguno de los lugares consultados, pero seguramente corresponde al rosal de flores blancas de la mosqueta, cuyo suave aroma menciona Laguna $^{58}$. En la actualidad se confecciona aceite de sus frutos. Se entiende como un tipo de confecciones o fórmulas basadas en la rosa mosqueta. *(160)

\section{Rosmarinus officinalis L. LAMIACEAE}

Acto 1: «Aparejos para baños...romero...» (ver Adiantum capillus-veneris).

Acto 7: «Todo olor fuerte es bueno, así como...de romero...» (ver Artemisia absinthium).

Se trata de una planta utilizada desde antiguo como medicinal y ornamental por sus propiedades antisépticas y su aroma característico. ${ }^{*}(170)$.

\section{Ruta chalepensis L. RUTACEAE}

Acto 4: ¡Jesú, señora! más conocida es esta vieja que la ruda».

Acto 7: «Todo olor fuerte es bueno, así como...ruda...» (ver Artemisia absinthium).

Aunque todas las especies de ruda comparten en mayor o menor medida el olor característico, la especie que se cultiva con más frecuencia en España es $R$. chalepensis ${ }^{59}$ Otra especie, $R$. graveolens L., oriunda del E de la región mediterránea, era la más cultivada en Centroeuropa y la que venden en los viveros en la actualidad. R montana (L.) L. y $R$. angustifolia (Willd.) Pers. se encuentran con frecuencia silvestres en España. Planta utilizada para regular el menstruo, por sus propiedades emenagogas, y como abortiva, además de para aclarar la vista; era de uso muy común en tiempos pasados. *(173).

\section{Saccharum officinarum L. POACEAE}

Acto 1: «hacía solimán,...azucarados...» (ver Asphodelus albus).

El azúcar se ha obtenido desde antiguo de la caña de azúcar, hasta que en el siglo XIX se comenzó a extraer de la remolacha azucarera. Aún persisten algunos ingenios de caña de azúcar en el sur de España.

\section{Salix viminalis L. SALICACEAE}

Acto 4: «Que, a la mi fe, la vejez no es sino ..., cayado de mimbre, que con poca carga se doblega».

El mimbre se obtenía y obtiene preferentemente de esta especie de sauce, aunque también de otras. Como bien se indica, es poco apropiada para bastones, por su flexibilidad, por lo que se usa para tejer cestos. La corteza de los sauces ha sido utilizada como curativa.

\section{Sambucus nigra L. CAPRIFOLIACEAE}

Acto 1: «Aparejos para baños...saúco...» (ver Adiantum capillus-veneris).

Las flores semimágicas del saúco, que se colectan la noche de San Juan, con lo cual adquieren más poder curativo, son las del arbolillo llamado también sabuco. ${ }^{60}$ En el centro y norte de Europa

\section{LAGUNA (1555).}

59 San Miguel, E. (2003), Rue (Ruta L., Rutaceae) in traditional Spain: frecuency and distribution of its medicinal and symbolic applications, Economic Botany, 57 (2), pp. 231-244.

60 Pardo de Santayana, M. (1999), Plantas y magia en la noche de San Juan, Quercus, 160, p. 37. 
es costumbre hacer jarabe de flor de saúco, para luego disolverlo en agua y beberlo. Esta planta contiene mucha vitamina C. *(133).

\section{Scorpiurus muricatus L. FABACEAE}

Acto 1: «Los aceites que sacaba para el rostro...granillo...» (ver Citrus limon).

El granillo, según Laza, se refiere a esta especie, conocida en Andalucía y Levante como granillo de oveja. Este nombre aparece registrado por distintos autores. ${ }^{61} . *(136)$.

\section{Secale cereale L. POACEAE}

Acto 1: «hacía lejias para enrubiar, de sarmientos, de carrasca, de centeno, de marrubios, con salitre, con alumbre y millifolia y otras diversas cosas».

La novedad de la cita de la Celestina es que esta planta era usada para aclarar el color del cabe1lo. *(113).

\section{Solanum nigrum L. SOLANACEAE}

Acto 1: «Aparejos para baños hoja tinta...» (ver Adiantum capillus-veneris).

Cantalapiedra (2000) considera que la hoja tinta podría corresponder a la hierba mora, según los diccionarios de Autoridades y de la RAE. *(166)

\section{Stellaria media (L.) Vill. CARYOPHYLLACEAE}

Acto 1: «Los aceites que sacaba para el rostro...hierba pajarera» (ver Citrus limon).

El nombre de hierba pajarera, más conocida como pamplina, proviene de que tradicionalmente se le ha dado de comer a los pájaros de jaula. Al parecer la Celestina la incluía en sus recetas de aceites o cremas para la cara. Esta especie contiene saponinas. Se utiliza popularmente por sus propiedades vulnerarias y astringentes, que puede ser debido a las saponinas que contiene. ${ }^{*}(165)$.

\section{Styrax benzoin Dryander STYRACACEAE}

Acto 1: «Y en su casa hacía perfumes, falsaba...menjuí...» (ver Abelmoschus moschatus).

Acto 1: «Los aceites que sacaba para el rostro...menjuí...» (ver Citrus limon).

El menjuy o benjuy es un producto vegetal resinoso que se obtiene de esta planta; su uso es bien antiguo como oficinal; suele denominarse en castellano benjuí de Sumatra. Además se conoce el benjuí de Siam, nombre este último, que se encuentra asociado a la perfumería. Este producto, que es conocido en España al menos desde el siglo XV, ha perdurado en una especialidad farmacéutica (REGAL), de mediados del siglo pasado, e incluso en los inicios del actual.62*(105).

\section{Styrax officinalis L. STYRACACEAE}

Acto 1: «Y en su casa hacía perfumes, falsaba estoraques...» (ver Abelmoschus moschatus).

Acto 1: «Los aceites que sacaba para el rostro...estoraque...» (ver Citrus limon).

Estoraques son en general un tipo de bálsamos o resinas aromáticas, diversificados por falsificación, ya que, como señala Laza «fue el destino de este producto balsámico ser siempre adulterado, habiendo decidido las modernas Farmacopeas no considerar como oficinal más que el producto obtenido por ebullición y presión de la corteza del Liquidambar orientale». Con el nombre de estoraque se ha conocido en España sobre todo a la resina de la especie que se considera. Los pro-

61 Morales, R., Macía, M.J., Dorda, E. y García-Villaraco, A. (1996), Nombres vulgares, II. Archivos de Flora iberica, 7, 325 pp.

62 Vanaclocha, B. y CaÑIgueral, S. (eds.) (2003), Fitoterapia. Vademécum de prescripción, Barcelona, Masson. 
ductos de Liquidambar orientalis Mill. y L. styraciflua L. (Hamamelidaceae) son conocidos como estoraque líquido. La primera es especie americana, la segunda del Viejo Mundo. El estoraque se quemaba para conseguir un aroma agradable que diera un buen ambiente en las casas, además de como desinfectante. $*(131)$.

\section{Tribulus terrestris L. ZYGOPHYLLACEAE}

El autor, excusándose: «Y encima de rosas, sembrar mil abrojos»

Se trata de una especie rastrera que tiene unos frutos con espinas muy punzantes.

\section{Triticum aestivum L. POACEAE}

Acto 1: «ninguno venía sin torrezno, trigo, harina o jarro de vino y de las otras provisiones que podían a sus amas hurtar»;

Acto 1: «Yo te le traeré manso y benigno a picar el pan en el puño y seremos dos a dos»

Acto 1: «Bien harás, y luego vamos. Que no se debe dejar crecer la hierba entre los panes ni la sospecha en los corazones de los amigos; sino limpiarla luego con el escardilla de las buenas obras»».

Acto 3: «Al primer desconcierto que vea en este negocio, no coma más su pan».

Acto 3: «Si yo traía el pan, ella la carne»

Acto 3: «Pues cuando tu naciste ya comía yo pan con corteza»

Acto 4: «que no solo de pan viviremos?»

Acto 4: «una blanca para pan y un cuarto para vino»

Acto 4: «pan y vino anda camino, que no mozo garrido»

Acto 8: «Pan blanco, vino de Monviedro, un pernil de tocino, y más seis pares de pollos, que trajeron estotro día los renteros de nuestro amo».

Acto 9: «Que un cortezón de pan ratonado me basta para tres días:»

Acto 9: «de hombre tan rico, que con los salvados de su casa podría yo salir de lacería, según lo mucho le sobra».

Acto 9: «vale más una migaja de pan con paz, que toda la casa llena de viandas con rencilla».

Acto 9: «Y enviaban sus escuderos y mozos a que me acompañasen, y apenas era llegada a mi casa cuando entraban por mi puerta muchos pollos y gallinas, anserones, anadones, perdices, tórtolas, perniles de tocino, tortas de trigo, lechones».

Acto 9: «Pues, otros curas sin renta, no era ofrecido el bodigo, cuando, en besando el feligrés la estola, era del primer voleo en mi casa».

Acto 11: «Cata, madre, que así se suelen dar las zarazas en pan envueltas, porque no las sienta el gusto».

Acto 12: «Bien empleado es el pan que tan esforzados sirvientes comen».

Acto 12: «A perro viejo no cuz cuz».

Acto 14: «pero con su pan se la coma, que bien caro le cuesta»;

Acto 14: «iOh cruel juez, y qué mal pago me has dado del pan que de mi padre comiste!»

Las referencias al trigo y al pan son, como se podía esperar, bien numerosas, dada la importancia de este producto básico en la vida cotidiana, que queda bien reflejado en la obra literaria. En total son 18 las citas que se refieren al trigo, pan o derivados. El bodigo era un panecillo hecho con la harina más fina o flor de la harina, para ser ofrecido como ofrenda en la iglesia. El cuz cuz se hace con harina de trigo. Y el salvado es un subproducto que hoy se utiliza en dietética por su contenido en fibra, para regular las funciones digestivas; es la cáscara del grano de los cereales, sobre todo del trigo. También hay una alusión a panes, refiriéndose a la planta del trigo (Acto 1).

Tuber sp. HONGO

Concluye el autor: «Con motes y trufas del tiempo más viejo / escritas a vueltas le ponen sabor». 
El término «trufa» alude probablemente, aunque aquí en sentido figurado, a algún hongo subterráneo del género Tuber. En la frase parece que se hace un juego de palabras con el doble sentido de comestible y embuste.

\section{Ulmus minor L. ULMACEAE}

Acto 12: «Y también yo tenía mis cuestiones con los que tiraban piedras a los pájaros, que asentaban en un álamo grande que tenía, porque dañaba la hortaliza».

En general, el nombre de álamo en aquella época se refiere al árbol que en la actualidad se suele denominar olmo.

\section{Urginea maritima (L.) Baker LILIACEAE}

Acto 1: «Tenía en un tabladillo...cebolla albarrana...» (ver en Cornus sanguinea).

La cebolla albarrana no parece de mucha utilidad a la hora de componer virgos. Se trata de una planta tóxica, que se ha utilizado para ahuyentar roedores. En tiempos pasados, y debido a que su cebolla contiene compuestos parecidos a la digitalina, se ha usado como tónico cardíaco. *(112).

\section{Vateria indica L. DIPTEROCARPACEAE}

Acto 1: «Y en su casa hacía perfumes, falsaba...ánimes...» (ver Abelmoschus moschatus).

Ánime es el nombre de una resina aromática que segrega un árbol oriundo de la India; los árabes o los portugueses trajeran probablemente este producto a la Península ibérica. Dicho árbol se utiliza como ornamental en su lugar de origen. Laza comenta que este nombre es el de la especie Hymenaea courbaril L. (Fabaceae), también conocida como copal de Brasil o curbaril, especie que sustituyó al ánime del Viejo Mundo. Es difícil que fuera conocida dicha especie americana por el autor de la obra. *(97).

\section{Vicia faba L. FABACEAE}

Acto 1: «Da Dios habas a quien no tiene quijadas».

Acto 1: «Y en otro apartado tenía para remediar amores...haba morisca...» (ver Athyrium filix-femina).

Las habas, cuando se toman como alimento, son pesadas de digerir. Al parecer fueron muy usadas para sortilegios amorosos en Madrid y Toledo por mujerzuelas, cortesanas, mancebas y enamoradas.

Pudiera ser que «haba morisca» indicara algo distinto a haba a secas. Río ${ }^{63}$ menciona, como fríjoles de Castilla, unas alubias blancas que eran muy conocidas y fueron llevadas a América (citando a Bernabé Cobo). Si el nombre de «haba morisca» en el siglo XV correspondiera a esos fríjoles de Castilla, se trataría de la especie Vigna unguiculata (L.) Walpers, que por ser africana de origen podría haber recibido el apelativo «morisca». En ese caso, esta segunda cita habría que considerarla dentro de la especie correspondiente, que se encuentra más abajo. *(139).

\section{Vicia sativa L. FABACEAE}

Acto 1: «Los aceites que sacaba para el rostro...arvejas...» (ver Citrus limon).

Las arvejas o vezas se utilizan en la actualidad casi exclusivamente para forraje. Su harina se usaba en medicina popular por su propiedad emoliente, para ablandar forúnculos, o por su acción protectora y antiinflamatoria sobre la piel. *(100).

Vigna unguiculata L. FABACEAE

Acto 1: «Los aceites que sacaba para el rostro...carillas...» (ver Citrus limon).

63 Del Río, J. (1990), La transformación ecológica indiana. En FERnÁNDEZ, J. y GonZÁLEZ, I. (eds.), La agricultura viajera, Madrid, Real Jardín Botánico, CSIC y Ministerio de Agricultura, pp. 15-35. 
Las judías carillas eran conocidas en la Península Ibérica desde antiguo, ya que es especie procedente del Viejo Mundo. Después de la introducción de las judías americanas, el cultivo de esta especie perdió importancia. *(165).

\section{Viola odorata L. VIOLACEAE}

Acto 1: «Los aceites que sacaba para el rostro...violetas...» (ver Citrus limon).

El perfume de violeta era uno de los más caros, hasta que fue sintetizado su principio aromático. $*(189)$.

\section{Viscum album L. VISCACEAE}

Acto 17: «No es otra cosa la color y albayalde, sino pegajosa liga en que se traban los hombres».

La liga era obtenida del muérdago, que la tiene de natural en sus frutos para facilitar su diseminación por las aves.

\section{Vitis vinifera L. VITACEAE}

Acto 1: «Oye a Salomón do dice que las mujeres y el vino hacen a los hombres renegar»

Acto 1: «No has rezado en la festividad de San Juan do dice: 'Las mujeres y el vino hacen a los hombres renegar'»

Acto 1: «Labradores en las huertas, en las aradas, en las viñas, en las segadas, con ella pasan el afán cotidiano».

Acto 1: «ninguno venía sin torrezno, trigo, harina o jarro de vino y de las otras provisiones que podían a sus amas hurtar»;

Acto 1: «hacía solimán,....agraz, de mosto...«(ver Asphodelus albus).

Acto 1: «Sacaba aguas para oler...polvorizadas con vino» (ver Citrus aurantium).

Acto 1 «hacía lejias para enrubiar, de sarmientos, de carrasca, de centeno, de marrubios, con salitre, con alumbre y millifolia y otras diversas cosas».

Acto 3: «¿Tengo otra casa o viña?»

Acto 4: «una blanca para pan y un cuarto para vino»

Acto 4: «Jamás me acosté sin comer una tostada en vino y dos docenas de sorbos, por amor de la madre, tras cada sopa».

Acto 4: «pan y vino anda camino, que no mozo garrido»

Acto 8: «Pan blanco, vino de Monviedro, un pernil de tocino, y más seis pares de pollos, que trajeron estotro día los renteros de nuestro amo».

Acto 9: «Por una vez que haya de salir donde pueda ser vista, enviste su cara con hiel y miel, con uvas tostadas y higos pasados, y con otras cosas, que por reverencia de la mesa dejo de decir».

Acto 9: «¿Pues vino, no me sobraba? De lo mejor que se bebía en la ciudad, venido de diversas partes, de Monviedro, de Luque, de Toro, de Madrigal, de San Martín y de otros muchos lugares», Concluye el autor: «Vinagre con hiel fue su potación»;

Las referencias al vino son numerosas, ya que, igual que el trigo, era un producto de primera necesidad. Además se citan otros términos relativos a esta especie vegetal, como uva, viña, sarmientos, mosto, agraz, destilados, vinagre. Cuando en el acto 9 se citan lugares famosos por su vino, probablemente se correspondan a Monviedro en Valencia, Luque en Córdoba, Toro en Zamora, Madrigal de la Vera en Cáceres y San Martín de Valdeiglesias en Madrid. Estas podrían ser algunas de las primeras menciones de «denominaciones de origen» a finales del siglo XV. *(187).

\section{Ziziphus jujuba Miller RHAMNACEAE}

Acto 1: «Los aceites que sacaba para el rostro....azofeifas...» (ver Citrus limon).

De esta también se obtenía aceites para la cara. Probablemente se trate del aceite de la semilla, ya que la parte carnosa del fruto no es oleaginosa. El fruto se usa en licor como reconstituyente, según receta de la medicina tradicional china. $*(103)$. 


\section{ANEXO 2: ESPECIES ANIMALES}

Accipiter nisus

Prólogo: «Las más viven de rapiña, como halcones y águilas y gavilanes».

Alectoris rufa

Acto 7: «Todo olor fuerte es bueno, así como...de perdiz...» (ver Artemisia absinthium).

Acto 7: «Una perdiz sola por maravilla vuela».

Acto 8: «Que con la mucha que en su gesto contemplas, no puedes ver de encandelado, como perdiz con la calderuela».

Acto 9: «Y enviaban sus escuderos...perdices...» (ver en Triticum aestivum).

Acto 10: «el falso boyzuelo con su blando cencerrar trae las perdices a la red»;

Anas platyrhynchus

Acto 9: «Y enviaban sus escuderos...anadones...» (ver en Triticum aestivum).

\section{Anser anser}

Acto 9: «Y enviaban sus escuderos...anserones...» (ver en Triticum aestivum).

Aquila chrysaetos

Prólogo: «Las más viven de rapiña, como halcones y águilas y gavilanes».

Acto 1: «Y en otro apartado tenía para remediar amores...águila...» (ver Athyrium filix-femina).

\section{Ardea cinerea}

Acto 1: «Y los untos y mantecas que tenía, es hastío de decir: de vaca, de oso, de caballos y de camellos, de culebra y de conejo, de ballena, de garza y de alcaraván y de gamo y de gato montés y de tejón, de arda, de erizo, de nutria».

Acto 1 «Adelgazaba los cueros con zumos de...garza...» (ver Citrus limon).

Aves

Prólogo: «De un ave llamada rocho, que nace en el índico mar de Oriente»

Se trata de un ave mítica. Además hay otras citas como ave.

Bos primigenius

Acto 1: «como ligeros toros; sin frenos saltan por las barreras».

Acto 1: «No has leido de Pasife con el toro, de Minerva con el can»

Acto 1: «Parece al amante que atrás queda, todos pasan todos rompen, pungidos y esgarrochados, como ligeros toros, sin freno saltan por las barreras».

Acto 1: «Y los untos y mantecas que tenía...vaca...» (ver en Ardea cinerea).

Acto 9: «poniendo cada día la vida al tablero, esperando toros, corriendo caballos, tirando barra»,

Acto 10: «el falso boyzuelo con su blando cencerrar trae las perdices a la red»;

Acto 12: «Las sucias moscas nunca pican sino los bueyes magros y flacos; los gozques ladradores a los pobres peregrinos aquejan con mayor ímpetu».

Burrhinus oedicnemus

Acto 1: «Y los untos y mantecas que tenía...alcaraván...» (ver en Ardea cinerea).

Buthus occitanus

Acto 1: «iComo cola de alacrán!» 
Camelus ferus

Acto 1: «Y los untos y mantecas que tenía...camellos...» (ver en Ardea cinerea).

\section{Canis domesticus}

El autor a su amigo: «echando mis sentidos por ventores y mi juicio a volar»

Prólogo: «una especie a otra persigue. El león al lobo, el lobo la cabra, el perro la liebre»

Acto 1: «No has leido de Pasife con el toro, de Minerva con el can»

Acto 1: «Si pasa por los perros, aquello suena su ladrido, si está cerca las aves, otra cosa no cantan, si cerca los ganados, balando lo pregonan, si cerca las bestias, rebuznando dicen: ¡Puta vieja!; las ranas de los charcos otra cosa no suelen mentar».

Acto 2: « Nunca más perro a molino!»

Acto 4: «Ni perro me ha ladrado, ni ave negra he visto, tordo ni cuervo ni otras nocturnas».

Acto 4: «El perro con todo su ímpetu y braveza, cuando viene a morder, si se le echan en el suelo no hace mal; esto de piedad».

Acto 12: «Las sucias moscas nunca pican sino los bueyes magros y flacos; los gozques ladradores a los pobres peregrinos aquejan con mayor ímpetu».

Acto 14: «O si por caso los ladradores perros con sus crueles dientes que ninguna diferencia saben hacer ni acatamiento de personas, le hayan mordido»;

Canis lupus

Prólogo: «una especie a otra persigue. El león al lobo, el lobo la cabra, el perro la liebre»

Acto 1: «¿Lobitos en tal gestico?»

Acto 3: «Entra en la cámara de los ungüentos y en la pelleja del gato negro donde te mandé meter los ojos de la loba, le hallarás, y baja la sangre del cabrón, y unas poquitas de las barbas que tu le cortaste».

Acto 19: «Saltos de gozo infinito / da el lobo viendo ganado; / con las tetas, los cabritos; / Melibea con su amado».

\section{Capra aegagrus}

Prólogo: «una especie a otra persigue. El león al lobo, el lobo la cabra, el perro la liebre»

Acto 3: «Entra en la cámara de los ungüentos y en la pelleja del gato negro donde te mandé meter los ojos de la loba, le hallarás, y baja la sangre del cabrón, y unas poquitas de las barbas que tu le cortaste». Acto 19: «Saltos de gozo infinito / da el lobo viendo ganado; / con las tetas, los cabritos; / Melibea con su amado».

\section{Capreolus capreolus}

Acto 1: «Adelgazaba los cueros con zumos...corzo...» (ver Citrus limon).

Cervus elephas

Acto 1: «Y en otro apartado tenía para remediar amores...ciervo...» (ver Athyrium filix-femina).

\section{Ciconia ciconia}

Acto 3: «Las cigüeñas mantienen otra tanto tiempo a sus padres viejos en el nido, cuanto ellos le dieron cebo siendo pollitos».

\section{Corallum rubrum}

Acto 9: «Esto quita la tristeza del corazón más que el oro ni el coral; esto da esfuerzo al mozo y al viejo fuerza, pone color al descolorido, coraje al cobarde, al flojo diligencia, conforta los cerebros, saca el frío del estómago, quita el hedor del aliento» 
Corvus corax

Acto 4: «Ni perro me ha ladrado, ni ave negra he visto, tordo ni cuervo ni otras nocturnas».

Acto 14: «¿Por qué quisiste que dijesen del monte sale con que se arde, y que crié cuervo que me sacase el ojo?»

Coturnix coturnix

Acto 1: «Y en otro apartado tenía para remediar amores...codornices...» (ver Athyrium filixfemina).

Cygnus olor

Acto 19: «Por qué no me dejabas echar palabras sin seso al aire con mi ronca voz de cisne?»

Dama dama

Acto 1: «Y los untos y mantecas que tenía...gamo»

Dragón

Acto 3: «y hacia la mano derecha hallarás un papel escrito con sangre de murciélago debajo de aquel ala de dragón a que sacamos ayer las uñas».

Se debe referir al murciélago.

\section{Equus africanus}

Acto 1: «Más en asnos». ¿Qué dices? Dije que esos tales no serían cerdas de asno».

Acto 1: «do vino el asno verná el albarda»

Acto 1: «Jo, que te estriego, asna coja»

Acto 1: «Este es el deleite, que lo ál, mejor lo hacen los asnos en el prado».

Acto 1: «¿Qué es afecto, asnillo?

Acto 1: «Si pasa por los perros, aquello suena su ladrido, si está cerca las aves, otra cosa no cantan, si cerca los ganados, balando lo pregonan, si cerca las bestias, rebuznando dicen: ¡Puta vieja!; las ranas de los charcos otra cosa no suelen mentar».

Acto 1: «Y en otro apartado tenía para remediar amores....asno...» (ver Athyrium filix-femina).

Acto 7: «Llégate aca; asno».

Acto 8: «Allá irás con el diablo tu y malos años; y en tal hora comieses el diacitrón, como Apuleyo el veneno que le convirtió en asno».

Acto 17: "Así sé yo tratar los tales, así salen de mis manos los asnos apaleados como este y los locos corridos y los discretos espantados y los devotos alterados y los castos encendidos».

\section{Equus cavallus}

Acto 1: «Aquí estoy, señor, curando de estos caballos».

Acto 1: «Y los untos y mantecas que tenía...caballos...» (ver en Ardea cinerea).

Acto 1: «Y en otro apartado tenía para remediar amores...caballo...» (ver Athyrium filix-femina).

Acto 2: «Saquen un caballo»

Acto 2: «¿Relinchais don caballo?

Acto 2: «¿Viene ese caballo?»

Acto 8: «No digo mal en esto, sino que se eche otra sardina para el mozo de caballos, pues tu tienes amiga»

Acto 8: «ni comeré hasta entonces, aunque primero sean los caballos de Febo apacentados en aquellos verdes prados que suelen, cuando han dado fin a su jornada».

Acto 9: «poniendo cada día la vida al tablero, esperando toros, corriendo caballos, tirando barra», Acto 15: «¿Por qué jugaste tu el caballo, tahúr, vellaco?» 
Acto 17: «Los otros de verme ir con la luna de noche a dar agua a mis caballos, holgando y habiendo placer»,

\section{Erinaceus europaeus}

Acto 1: «Y los untos y mantecas que tenía erizo...» (ver en Ardea cinerea).

Acto 1: «Y en otro apartado tenía para remediar amores...erizo...» (ver Athyrium filix-femina).

\section{Eubalaena glacialis}

Acto 1: «Y los untos y mantecas que tenía...ballena...» (ver en Ardea cinerea).

Falco nebli

Acto 2: «Señor, porque perderse el otro día el neblí fue causa de tu entrada en la huerta de Melibea»;

\section{Falco peregrinus}

Prólogo: «Las más viven de rapiña, como halcones y águilas y gavilanes».

Acto 1: «Entrando Calixto una huerta en pos de un falcón suyo»,

Falco rusticolus

Acto 1: «Abatiose el gerifalte y vínele a enderezar en el alcándara».

Felis sylvestris

Acto 1: «Y los untos y mantecas que tenía...gato montés...» (ver en Ardea cinerea).

Acto 3: «Entra en la cámara de los ungüentos y en la pelleja del gato negro donde te mandé meter los ojos de la loba, le hallarás, y baja la sangre del cabrón, y unas poquitas de las barbas que tu le cortaste».

Formicidae

El autor, excusándose: «Como la hormiga que deja de ir, / Holgando por tierra, con la provisión»

Gallus domesticus

Prólogo: «Hasta los groseros milanos insultan dentro en nuestras moradas los domésticos pollos» Acto 4: «Pues la aves, ninguna cosa el gallo, come que no participe y llame las gallinas a comer de ello».

Acto 8: «y más seis pares de pollos que trajeron estotro día los renteros de nuestro amo»

Acto 9: «Ven acá, mala mujer, la gallina havada no parece; pues búscala presto, si no, en la primera blanca de tu soldada la contaré».

Acto 9: «Y enviaban sus escuderos...gallinas...» (ver en Triticum aestivum).

Acto 12: «¿Con una oveja mansa teneis vosotros manos y braveza? ¿Con una gallina atada?»

Acto 17: «Y esto hecho, contaré mis gallinas, haré mi cama, porque la limpieza alegra el corazón»;

\section{Hirudo medica}

Acto 1: «Como la sanguijuela saca la sangre, desagradecen, injurian, olvidan servicios, niegan galardón».

\section{Hirundo rustica}

Acto 7: «Una golondrina no hace verano».

Homo sapiens

Acto 1: «Y en otro apartado tenía para remediar amores...niño...» (ver Athyrium filix-femina). 
Lepus granatensis

Prólogo: «una especie a otra persigue. El león al lobo, el lobo la cabra, el perro la liebre»

\section{Loxodontha africana}

Prólogo: «El elefante, animal tan poderoso y fuerte, se espanta y huye de la vista de un suzuelo ratón, y aun de solo oírle toma gran temor».

La otra especie de proboscídeo actual es el elefante indio.

Luscinia megarhynchos

Acto 19: «Papagayos, ruiseñores / que cantais al alborada; / llevad nueva a mis amores / como espero aquí asentada».

\section{Lutra lutra}

Acto 1: «Y los untos y mantecas que tenía...nutria» (ver en Ardea cinerea).

\section{Margaritifera margaritifera}

Acto 14: «iCon cuántas lágrimas, que parecían granos de aljófar,...!»

Estas perlas pequeñas de forma irregular las producen los mejillones de río. Uno de los más comunes es la especie que se cita.

\section{Meles meles}

Acto 1: «Y los untos y mantecas que tenía...tejón...» (ver en Ardea cinerea).

Acto 1: «Y en otro apartado tenía para remediar amores...tejón...» (ver Athyrium filix-femina).

\section{Milvus regalis}

Prólogo: «Hasta los groseros milanos insultan dentro en nuestras moradas los domésticos pollos»

\section{Moschus moschiferus}

Acto 1: «Y en su casa hacía perfumes, falsaba....almizcles...» (ver Abelmoschus moschatus).

Acto 19: «Echaba de sí en bullendo un olor de almizque; yo hedía al estiércol que llevaba dentro de los zapatos».

El ciervo almizclero, de Asia, tiene unas glándulas en el vientre que segregan este producto cuando el animal está en celo.

\section{Mus musculus}

Prólogo: «El elefante, animal tan poderoso y fuerte, se espanta y huye de la vista de un suzuelo ratón, y aun de solo oírle toma gran temor».

Acto 7: «No hay cosa más perdida, hija, que el mur que no sabe sino un horado».

\section{Musca domestica}

Acto 12: «Las sucias moscas nunca pican sino los bueyes magros y flacos; los gozques ladradores a los pobres peregrinos aquejan con mayor ímpetu».

\section{Ofidios}

Prólogo: «Pues entre los animales ningún género carece de guerra: peces, fieras, aves, serpientes; de lo cual todo, una especie a otra persigue».

Prólogo: «Entre las serpientes, el vajarisco, crió la natura tan ponzoñoso y conquistador de todas las otras, que con su silbo las asombra y con su venida las ahuyenta y desparce».

Acto 1: «Y los untos y mantecas que tenía...culebra...» (ver en Ardea cinerea). 
Acto 15: «las hierbas deleitosas donde tomais los hurtados solaces se conviertan en culebras»; Acto 21: «prado lleno de serpientes»,

En la segunda cita, con vajarisco igual pudiera referirse al basilisco, animal fabuloso al que se atribuía el poder de matar con la mirada, aunque después se le dio este nombre a un saurio centroamericano (Basiliscus americanus).

Oryctolagus cuniculus

Acto 1: «Y los untos y mantecas que tenía...conejo...» (ver en Ardea cinerea).

\section{Ostraea edulis}

Acto 1: «Las manos pequeñas en mediana manera, de dulce carne acompañadas; los dedos luengos; las uñas en ellos largas y coloradas, que parecen rubíes entre perlas».

Acro 1: «iNeciuelo, loquito, algelico, perlica, simplecico!»

Como es sabido las perlas son formaciones de nácar producidas por las ostras, moluscos marinos.

Ovis orientalis

Acto 9: «Y enviaban sus escuderos...lechones» (ver en Triticum aestivum).

Acto 11: "Así como corderica mansa que mama su madre y la ajena»,

Acto 12: «¿Con una oveja mansa teneis vosotros manos y braveza? ¿Con una gallina atada?»

Acto 14: «cata que el buen pastor es propio trasquilar sus ovejas y ganado, pero no destruirlo y estragarlo».

\section{Panthera leo}

Prólogo: «una especie a otra persigue. El león al lobo, el lobo la cabra, el perro la liebre»

Peces

Prólogo: «Pues entre los animales ningún género carece de guerra: peces, fieras, aves, serpientes; de lo cual todo, una especie a otra persigue».

Prólogo: «Pues no menos disensiones naturales creemos haber en los pescados; pues es cosa cierta gozar la mar de tantas formas de peces, cuantas la tierra y el aire cría de aves y animalias, y muchas más».

\section{Pelecanus onocrotalus}

Acto 3: «El pelícano rompe el pecho por dar a sus hijos a comer de sus entrañas».

\section{Pediculus humanus}

Acto 1: «¿Rieste, landrecilla, hijo?»

Acto 1: «iMala landre te mate!»

Se refiere a la liendre.

Physeter macrocephalus

Acto 1: «Y en su casa hacía perfumes, falsaba...ámbar...» (ver Abelmoschus moschatus).

El ámbar al que se refiere es sin duda al conocido como ambar gris, producto aromático de origen animal, que se obtiene del cachalote, y que es el que se utiliza en perfumería. Laguna, en la página 29 de su traducción del Dioscórides, parece referirse a lo que hoy se llama ámbar gris mientras que en las páginas 67-68 se refiere sin duda al amarillo, del cual tenía muestras con insectos incluidos. 
Pica pica

Acto 9: «¿Quien mostro a las picazas y papagallos emitir nuestra propia habla con sus harpadas lenguas, nuestro órgano y voz, sino esta?»

Picaza es el nombre antiguo de la urraca.

Primate

Acto 1: «Lo de tu abuela con el simio, ¿hablilla fue? Testigo es el cuchillo de tu abuelo».

Psittacidae

Acto 9: «¿Quién mostró a las picazas y papagallos emitir nuestra propia habla con sus harpadas lenguas, nuestro órgano y voz, sino esta?»

Acto 19: «Papagayos, ruiseñores / que cantais al alborada; / llevad nueva a mis amores / como espero aquí asentada».

Quiróptero

Acto 3: «y hacia la mano derecha hallarás un papel escrito con sangre de murciélago debajo de aquel ala de dragón a que sacamos ayer las uñas».

\section{Rana ridibunda}

Acto 1: «Si pasa por los perros, aquello suena su ladrido, si está cerca las aves, otra cosa no cantan, si cerca los ganados, balando lo pregonan, si cerca las bestias, rebuznando dicen: ¡Puta vieja!; las ranas de los charcos otra cosa no suelen mentar».

\section{Sarcoptes scabiei}

Acto 1: «que es pensar sacar aradores a pala de azadón».

Se refiere sin duda al arador de la sarna.

\section{Sardina pilchardus}

Acto 8: «No digo mal en esto, sino que se eche otra sardina para el mozo de caballos, pues tu tienes amiga»

Sciurus vulgaris

Acto 1: «Y los untos y mantecas que tenía...arda...» (ver en Ardea cinerea).

Se refiere a la ardilla.

Streptopelia turtur

Acto 8: «Y las tórtolas que mando para hoy guardar, diré que hedían».

Acto 9: «Y enviaban sus escuderos...tórtolas...» (ver en Triticum aestivum).

Sturnus unicolor

Acto 4: «Ni perro me ha ladrado, ni ave negra he visto, tordo ni cuervo ni otras nocturnas».

Sus scrofa

Acto 1: «ninguno venía sin torrezno, trigo, harina o jarro de vino y de las otras provisiones que podían a sus amas hurtar»;

Acto 8: «un pernil de tocino»

Acto 9: «Y enviaban sus escuderos...perniles...» (ver en Triticum aestivum).

Se refiere al cerdo. 
Ursus arctos

Acto 1: «Y los untos y mantecas que tenía...oso...» (ver en Ardea cinerea).

Vipera latasti

Prólogo: «La víbora, reptilia o serpiente enconada, al tiempo de concebir, por la boca de la hembra metida la cabeza del macho y ella con el gran dulzor apriétale tamto que le mata y, quedando preñada, el primer hijo rompe los ijares de la madre, por do todos salen y ella muerta queda y el casi como vengador de la paterna muerte».

Acto 1: «Y en otro apartado tenía para remediar amores...víbora...» (ver Athyrium filix-femina).

Acto 3: «por la áspera ponzoña de las viboras»

Acto 10: «no de otra manera que, cuando vio en sueños aquel grande Alejandre, rey de Macedonia, en la boca del dragón la saludable raíz con que sanó a su criado Tolomeo del bocado de la víbora».

\section{Viverra civeta}

Acto 1: «Y en su casa hacía perfumes, falsaba...algalia...» (ver Abelmoschus moschatus).

Laza refiere que se trata de una sustancia aromática procedente de las glándulas de algunas especies asiáticas y africanas de un animal mamífero del género Viverra. Esta opinión coincide fundamentalmente con la del diccionario de la RAE en su primera acepción. La algalia del comercio procede sobre todo de la especie conocida como gato de algalia o civeta. ${ }^{*}(93)$.

Vulpes vulpes

Acto 12: «que aunque muda el pelo la raposa, su natural no despoja».

\section{NOMBRES VULGARES Y SUS CORRESPONDIENTES NOMBRES CIENTÍFICOS}

\section{PLANTAS}

abrojos Tribulus terrestris aceite Olea europaea agraz Vitis vinifera ajiensos Artemisia absinthium

álamo Ulmus minor alfócigos Pistacia vera algalia Abelmoschus moschatus algodones Gossypium herbaceum altramuces Lupinus albus ánimes Vateria indica arvejas Vicia sativa azafrán Crocus sativus azahar Citrus aurantium azofeifas Ziziphus jujuba azucarados Saccharum officinarum azucena Lilium candidum boca del dragón Antirrhinum majus

bodigo Triticum aestivum bujelladas Buxus sempervirens calabazas Lagenaria siceraria carillas Vigna unguiculata carrasca Quercus ilex cebolla albarrana Urginea maritima

centeno Secale cereale cepacaballo Equisetum arvense cipreses Cupressus sempervirens

clavellinas Dianthus plumarius col Brassica oleracea coronillas Melilotus officinalis culantrillo Adiantum capillus-veneris cuz cuz Triticum aestivum destilados Vitis vinifera diacitrón Citrus medica embelesada Plumbago europaea espantalobos Colutea arborescens espliego Lavandula latifolia estoraque Styrax officinalis flor salvaje Alchemilla vulgaris

gamones Asphodelus albus gramonilla Anthoxanthum odoratum

granillo Scorpiurus muricatus granos de helecho Athyrium filix-femina haba morisca Vicia faba habas Vicia faba harina Triticum aestivum hiedra Hedera helix hierba pajarera Stellaria media

higos Ficus carica higueruela Psoralea bituminosa hoja tinta Solanum nigrum hojaplasma Hypericum androsaemum 
incienso Boswellia sacra jazmín Jasminum officinale laurel blanco Laurus nobilis lechuga Lactuca sativa liga Viscum album limón Citrus limon lirios Iris germanica madreselva Lonicera periclymenum malvaviscos Althaea officinalis

manzana Malus domestica manzanilla Matricaria recutita marrubios Marrubium vulgare melón Cucumis melo menjuí Styrax benzoin millifolia Achillea millefolium mimbre Salix viminalis Mirra Commiphora abyssinica moho especie de musgo o de liquen mosquetadas Rosa moschata mosquetes Rosa moschata mostaza Brassica nigra mosto Vitis vinifera moxquete Rosa moschata Narciso Narcissus pseudonarcissus

neguilla Nigella sativa nueces Juglans regia pan Triticum aestivum panes Triticum aestivum pepitas Lagenaria siceraria pico de oro Cercis siliquastrum

piñones Pinus pinea poleo Mentha pulegium porradas Allium ampeloprasum

roble Quercus robur romero Rosmarinus officinalis

rosas Rosa sp.

ruda Ruta chalepensis salvados Triticum aestivum sanguino Cornus sanguinea sarmientos Vitis vinifera saúco Sambucus nigra tortarosa Daphne gnidium teraguncia Dracunculus vulgaris

trébol Melilotus officinalis trementina Pinus pinaster trigo Triticum aestivum trufas Tuber turbino Ipomoea turpethum uvas Vitis vinifera vinagre Vitis vinifera vino Vitis vinifera viña Vitis vinifera violetas Viola odorata

\section{ANIMALES}

águila Aquila chrysaetos alacrán Buthus occitanus alcaraván Burrhinus oedicnemus

algalia Viverra civeta almizcles Moschus moschiferus

almizque Moschus moschiferus ámbar Physeter macrocephalus

anadones Anas platyrhynchus anserones Anser anser aradores Sarcoptes scabiei arda Sciurus vulgaris asno, asna Equus africanus ballena Eubalaena glacialis bestias rebuznando Equus africanus

boyzuelo Bos primigenius bueyes Bos primigenius caballo Equus cavallus cabritos Capra aegagrus cabrón Capra aegagrus camellos Camelus ferus can Canis domesticus ciervo Cervus elephas cigüeñas Ciconia ciconia cisne Cygnus olor codornices Coturnix coturnix conejo Oryctolagus cuniculus coral Corallum rubrum corderica Ovis orientalis corzo Capreolus capreolus cuervo Corvus corax culebra Ofidios dragón Quirópteros erizo Erinaceus europaeus falcón Falco peregrinus gallina Gallus domesticus gallo Gallus domesticus gamo Dama dama garza Ardea cinerea gato Felis sylvestris gato montés Felis sylvestris gerifalte Falco rusticolus golondrina Hirundo rustica gozques Canis domesticus granos de aljófar Margaritifera margaritifera landrecilla Pediculus humanus lechones Ovis orientalis lobo, loba Canis lupus moscas Musca domestica mur Mus musculus murciélago Quiróptero neblí Falco nebli niño Homo sapiens nutria Lutra lutra oso Ursus arctos oveja Ovis orientalis papagallos Psittacidae pelícano Pelecanus onocrotalus perlas Ostraea edulis perdiz Alectoris rufa pernil Sus scrofa perro Canis domesticus picazas Pica pica pollos Gallus domesticus ranas Rana ridibunda raposa Vulpes vulpes ruiseñores Luscinia megarhynchos sanguijuela Hirudo medica sardina Sardina pilchardus serpientes Ofidios simio Primate tejón Meles meles tordo Sturnus unicolor toro Bos primigenius tórtolas Streptopelia turtur vaca $B$ os primigenius víbora Vipera aspis 
TABLA 1. RELACIÓN DE USOS DE PLANTAS Y DE ANIMALES UTILIZADOS

\begin{tabular}{|c|c|c|}
\hline Usos & ESPECIES VEGETALES UTILIZADAS & ESPECIES ANIMALES UTILIZADAS \\
\hline $\begin{array}{l}\text { Aceites para el } \\
\text { rostro }\left(\text { Acto } 1^{\circ}\right)\end{array}$ & $\begin{array}{l}\text { Citrus limon, Jasminum officinale, } \\
\text { Lagenaria siceraria, Lupinus albus, } \\
\text { Nigella sativa, Pinus pinea, Pistacia } \\
\text { vera, Scorpiurus muricatus, Stellaria } \\
\text { media, Styrax benzoin, Styrax } \\
\text { officinalis, Vicia sativa, Vigna } \\
\text { unguiculata, Viola odorata, Ziziphus } \\
\text { jujuba }\end{array}$ & \\
\hline $\begin{array}{l}\text { Adelgazar los } \\
\text { cueros }\left(\text { Acto } 1^{\circ}\right)\end{array}$ & Citrus limon, Ipomoea turpethum & $\begin{array}{l}\text { Ardea cinerea, Capreolus ca- } \\
\text { preolus }\end{array}$ \\
\hline $\begin{array}{l}\text { Aguas de rostro } \\
\left(\text { Acto } 1^{\circ}\right)\end{array}$ & $\begin{array}{l}\text { Asphodelus albus, Buxus sempervirens, } \\
\text { Colutea arborescens, Dracunculus } \\
\text { vulgaris, Saccharum officinarum, Vitis } \\
\text { vinifera }\end{array}$ & \\
\hline $\begin{array}{l}\text { Aguas para oler } \\
\left(\text { Acto } 1^{\circ}\right)\end{array}$ & $\begin{array}{l}\text { Citrus aurantium, Dianthus plumarius, } \\
\text { Jasminum officinale, Lonicera } \\
\text { periclymenum, Melilotus officinalis, } \\
\text { Rosa sp., Vitis vinifera }\end{array}$ & \\
\hline $\begin{array}{l}\text { Aparejos para baños } \\
\left(\text { Acto } 1^{\circ}\right)\end{array}$ & $\begin{array}{l}\text { Adiantum capillus-veneris, Alchemilla } \\
\text { vulgaris, Althaea officinalis, } \\
\text { Anthoxanthum odoratum, Brassica } \\
\text { nigra, Cercis siliquastrum, Daphne } \\
\text { gnidium, Laurus nobilis, Lavandula } \\
\text { latifolia, Matricaria recutita, Melilotus } \\
\text { officinalis, Psoralea bituminosa, } \\
\text { Rosmarinus officinalis, Sambucus } \\
\text { nigra, Solanum nigrum }\end{array}$ & \\
\hline $\begin{array}{l}\text { Untos y mantecas } \\
\left(\text { Acto } 1^{\circ}\right)\end{array}$ & & $\begin{array}{l}\text { Ardea cinerea, Bos primigenius, } \\
\text { Burrhinus oedicnemus, Camelus } \\
\text { ferus, Dama dama, Equus } \\
\text { cavallus, Erinaceus europaeus, } \\
\text { Felis sylvestris, Lutra lutra, } \\
\text { Eubalaena glacialis, Meles meles, } \\
\text { ofidios, Oryctolagus cuniculus, } \\
\text { Sciurus vulgaris, Ursus arctos }\end{array}$ \\
\hline $\begin{array}{l}\text { Componer virgos } \\
\left(\text { Acto } 1^{\circ}\right)\end{array}$ & $\begin{array}{l}\text { Cornus sanguinea, Equisetum } \\
\text { arvense, Hypericum androsaemum, } \\
\text { Urginea maritima }\end{array}$ & \\
\hline $\begin{array}{l}\text { Lejías para enrubiar } \\
\left(\text { Acto } 1^{\circ}\right)\end{array}$ & $\begin{array}{l}\text { Achillea millefolium, Marrubium } \\
\text { vulgare, Quercus ilex, Secale } \\
\text { cereale, Vitis vinifera }\end{array}$ & \\
\hline
\end{tabular}




\begin{tabular}{|c|c|c|}
\hline Usos & ESPECIES VEGETALES UTILIZADAS & ESPECIES ANIMALES UTILIZADAS \\
\hline Perfumes (Acto $1^{\circ}$ ) & $\begin{array}{l}\text { Abelmoschus moschatus, Rosa } \\
\text { moschata, Styrax benzoin, Styrax } \\
\text { officinalis, Vateria indica }\end{array}$ & Physeter macrocephalus \\
\hline $\begin{array}{l}\text { «Todo olor fuerte es } \\
\text { bueno» }\left(\text { Acto } 7^{\circ}\right) \\
\text { [para el mal de la } \\
\text { madre] }\end{array}$ & $\begin{array}{l}\text { Artemisia absinthium, Boswellia } \\
\text { sacra, Mentha pulegium, Rosa } \\
\text { moschata, Rosmarinus officinalis, } \\
\text { Ruta chalepensis }\end{array}$ & Alectoris rufa \\
\hline $\begin{array}{l}\text { «Para remediar } \\
\text { amores» }\left(\text { Acto } 1^{\circ}\right)\end{array}$ & $\begin{array}{l}\text { Athyrium filix-femina, Hedera helix, } \\
\text { Vicia faba }\end{array}$ & $\begin{array}{l}\text { Aquila chrysaetos, Cervus } \\
\text { elephas, Coturnix coturnix, } \\
\text { Equus africanus, Equus } \\
\text { cavallus, Erinaceus europaeus, } \\
\text { Homo sapiens, Meles meles, } \\
\text { Vipera aspis }\end{array}$ \\
\hline Uso mágico & Crocus sativus, Olea europaea & $\begin{array}{l}\text { Canis lupus, Capra aegagrus, } \\
\text { Felis sylvestris }\end{array}$ \\
\hline Para la cara & Ficus carica, Vitis vinifera & \\
\hline Antiveneno & Antirrhinum majus & \\
\hline Alimentación & $\begin{array}{l}\text { Citrus medica, Triticum aestivum, } \\
\text { Vitis vinifera }\end{array}$ & $\begin{array}{l}\text { Alectoris rufa, Anas } \\
\text { platyrhynchus, Anser anser, } \\
\text { Gallus domesticus, Ovis } \\
\text { orientalis, Sardina pilchardus, } \\
\text { Streptopelia turtur, Sus scrofa }\end{array}$ \\
\hline Uso tecnológico & Olea europaea & \\
\hline Cita real & Ulmus minor & \\
\hline $\begin{array}{l}\text { Citas en sentido } \\
\text { simbólico, en } \\
\text { dichos y en } \\
\text { observaciones }\end{array}$ & $\begin{array}{l}\text { Brassica oleracea, Citrus aurantium, } \\
\text { Commiphora abyssinica, Cucumis } \\
\text { melo, Cupressus sempervirens, } \\
\text { Gossypium herbaceum, Iris germanica, } \\
\text { Juglans regia, Lactuca sativa, Lilium } \\
\text { candidum, Malus domestica, musgo, } \\
\text { Narcissus pseudonarcissus, Pinus } \\
\text { pinaster, Plumbago europaea, Quercus } \\
\text { robur, Rosa sp., Ruta chalepensis, } \\
\text { Salix viminalis, Tribulus terrestris, } \\
\text { Triticum aestivum, Tuber, Vicia } \\
\text { faba,Viscum album, Vitis vinifera }\end{array}$ & $\begin{array}{l}\text { Alectoris rufa, Bos primigenius, } \\
\text { Buthus occitanus, Canis } \\
\text { domesticus, Canis lupus, Capra } \\
\text { aegagrus, Ciconia ciconia, } \\
\text { Cygnus olor, Equus africanus, } \\
\text { Hirudo medica, Hirundo } \\
\text { rustica, Luscinia } \\
\text { megarhynchos, Pelecanus } \\
\text { onocrotalus, Ovis orientalis, } \\
\text { Vulpes vulpes }\end{array}$ \\
\hline
\end{tabular}

Recibido: 26 de junio de 2009.

Aceptado: 28 de enero de 2010. 